\title{
QUEEN'S
UNIVERSITY
BELFAST
}

\section{Plasma metabolomic profiling based detection of drug specific responses to different bovine growth promoting regimes}

Kinkead, R. A., Elliott, C. T., Cannizzo, F. T., Biolatti, B., Gadaj, A., \& Mooney, M. H. (2018). Plasma

metabolomic profiling based detection of drug specific responses to different bovine growth promoting regimes. Food Control, 86, 146-158. https://doi.org/10.1016/j.foodcont.2017.10.036,

https://doi.org/10.1016/j.foodcont.2017.10.036

Published in:

Food Control

Document Version:

Peer reviewed version

Queen's University Belfast - Research Portal:

Link to publication record in Queen's University Belfast Research Portal

Publisher rights

(C) 2017 Elsevier Ltd.

This manuscript is distributed under a Creative Commons Attribution-NonCommercial-NoDerivs License

(https://creativecommons.org/licenses/by-nc-nd/4.0/), which permits distribution and reproduction for non-commercial purposes, provided the author and source are cited.

\section{General rights}

Copyright for the publications made accessible via the Queen's University Belfast Research Portal is retained by the author(s) and / or other copyright owners and it is a condition of accessing these publications that users recognise and abide by the legal requirements associated with these rights.

Take down policy

The Research Portal is Queen's institutional repository that provides access to Queen's research output. Every effort has been made to ensure that content in the Research Portal does not infringe any person's rights, or applicable UK laws. If you discover content in the

Research Portal that you believe breaches copyright or violates any law, please contact openaccess@qub.ac.uk. 
3 Ruth A. Kinkead ${ }^{1 *}$, Christopher T. Elliott ${ }^{1}$, Francesca T. Cannizzo ${ }^{2}$, Bartolomeo Biolatti ${ }^{2}$,

$4 \quad$ Anna Gadaj ${ }^{1}$, Mark H. Mooney ${ }^{1}$

$5{ }^{1}$ Institute for Global Food Security, School of Biological Sciences, Queen's University

6 Belfast, 18-30 Malone Road, Belfast, Co. Antrim, Northern Ireland BT9 5BN

$7 \quad{ }^{2}$ Department of Animal Pathology, University of Turin, Via L. Da Vinci 44, 10095 Grugliasco 8 (TO), Italy

*Corresponding Author: Ruth Ann Kinkead, Institute for Global Food Security, School of

Biological Sciences, Queen's University Belfast, 18-30 Malone Road, Belfast, Co. Antrim, Northern Ireland BT9 5BN, Tel No. +44 (0) 28909766 13, Fax +44 (0) 28909765 13, E-mail: rkinkead03@qub.ac.uk

\section{ABBREVIATIONS}

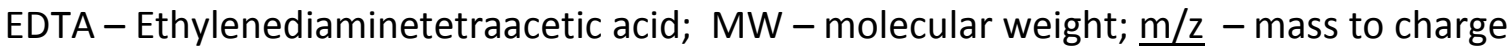
ratio; AMRTP - accurate mass and retention time pair; QC - quality control; FC - Fold Change; RSD - relative standard deviation; ANOVA - analysis of variance; UHPLC Ultra High Performance Liquid Chromatography; MS: Mass Spectrometry; PCA - Principal Component Analysis; OPLS-DA - Orthogonal Partial Least Squares Discriminant Analysis; VIP - variable importance of projection. 
The use of anabolic substances for growth promoting purposes in food producing animals is prohibited within the EU, yet ongoing applications of hormones such as oestradiol prove both difficult to detect and to distinguish from endogenous presence. Additionally, the misuse of glucocorticoid compounds (dexamethasone and prednisolone), which are permitted for therapeutic applications but can also promote improved animal health through long-term dosing, is reported to be increasing posing potential health concerns for consumers. Twenty-four male beef cattle were randomly assigned to four groups $(n=6)$ for experimental treatment over 40 days consisting of a control untreated group, and three treatment groups administered oestradiol, dexamethasone or prednisolone at levels known to reflect growth promoting practices. Untargeted metabolomic profiling of plasma collected from each animal midway through the study treatment period, were analysed by reverse phase separation employing an UHPLC-QTof-MS system operating in positive electrospray ionization mode. Metabolomics analysis revealed plasma metabolite perturbations common to all treated animals, with additional metabolites found to be specifically associated with the various differing growth promoting regimes. OPLS-DA modelling was used to discriminate plasma profiles of oestradiol, dexamethasone, or prednisolone from control untreated cohorts and found 56,48 and 58 ions altered by the administered treatments respectively. This culminated in 99 shared ions which could distinguish between plasma samples from treated versus untreated animals. Additional assessment of the metabolites found ions which were significantly altered in comparison to control animals, of which 3,11 and 8 ions were pertinent to oestradiol, dexamethasone or prednisolone administrations respectively. Incorporation of such markers to specific treatment types could be used at screening to facilitate further 
confirmatory analysis. Putative identification of these ions demonstrated mainly lipid components responsible for the growth promoter metabolomic effects alongside novel biomarker responses.

49

KEYWORDS: Cattle/Anabolic/Blood/Metabolite/Screening/Corticosteroid

\section{HIGHLIGHTS}

- Metabolomic profiling of bovine plasma outlines effect-based responses to growth promoter abuse and increases the capability to detect unsafe meat.

- Predictive modelling based on the plasma metabolome can differentiate between samples acquired from treated and untreated animals profiles based on common metabolites of interest.

- Monitoring of plasma metabolite markers specific to oestradiol, dexamethasone or prednisolone can be employed to identify the type of growth promoting regime employed

- Biomarkers responses reveal the distinct modes of action of the growth promoting agents relevant to their metabolic effects. 


\section{INTRODUCTION}

71 The implementation of screening based testing for detection of drug residues in food 72 producing animals is a required action within the European Union as stipulated in EC Regulation 178/2002 (2002a). Testing is assigned through National Residue Control Plans (NRCP) coordinated by European Residue Laboratories (EURLs) and results are reported to the European Food Safety Authority (EFSA) for annual review. EURLs are required to test $0.4 \%$ of slaughtered cattle numbers to meet minimum legislative requirements (Directive, 1996), and while routine regulatory monitoring finds sufficient compliance (DAFM, 2015), additional random on-farm sampling indicates continued illicit use of chemical agents within beef producing animals (Leporati et al. 2015; Imbimbo et al. 2012; Chiesa et al. 2017). The financial gains arising from illegal growth promoting administration encourages their use and exposes consumers to toxicological risk from contaminated food materials due to a combination of irregular drug use and ineffective testing (Ronquillo et al. 2017).

Current test methods are dependent on direct detection analysis of known compounds with confirmatory analysis typically reliant on gas (GC) or liquid chromatography (LC) coupled to mass spectrometry (MS) methods. Despite improved sensitivity through progress in these advanced technologies, analytical challenges to the detection of growth promoter use persist (Stolker et al. 2005; van Ginkel et al. 2016). These challenges include the detection of emerging unknown compounds, identification of drug use at low doses, and effective discrimination between endogenous forms of hormones and exogenous administrations either as therapeutics or for illicit purposes (Mooney et al. 2009; Pinel et al. 2010; Courtheyn et al. 2002). The latter includes glucocorticoid and oestradiol derivatives which are increasingly abused (EFSA, 2012; Sterk 
et al. 2014) due to their natural presence which is indistinguishable from external application. In this way confirmatory methods have incorporated isotope ratio (IRMS) techniques to discriminate exogenous metabolites based on the ratio of ${ }^{13} \mathrm{C} /{ }^{12} \mathrm{C}$ (Janssens et al. 2013). However, such analyses are only available through confirmatory test methods and robust screening methods are needed. As such more research in this field is be directed towards assessment of an animal's biological response to drug administration as a feasible alternative approach to discriminate biomarkers significant to xenobiotic exposure (Nebbia et al. 2011). In this way, Marin et al. (2008) were able to discern dexamethasone administration in finishing bulls by monitoring blood parameters, whilst Mooney et al. (2009) and Doué et al. (2015) have demonstrated biochemical screening of sex-hormone and bone markers as indicative of steroid misuse.

The range of sample matrices available for anabolic screening tests varies and is dependent on the regulatory body requirements on whether the drug to be tested is acquired from live or slaughtered animals (Directive, 1996). External biological material such as urine, hair and blood can be sampled on farm, whilst consumable parts are only available after slaughter. Some metabolomic studies have been conducted with urine to distinguish treatment of oestradiol, $\beta$-agonist and prohormones (Dervilly-Pinel et al. 2011; Jacob et al. 2015; Courant et al. 2009; Rijk et al. 2009), however there are concerns of false positive results due to faecal contamination (Arioli et al. 2010) and also endogenous prednisolone levels caused by stress (Pompa et al. 2011). Similarly, hair analysis may be subject to environmental contamination and obscured by the method of drug delivery, whilst drug residues are known to diffuse rapidly (Vanhaeke et al. 2011). For the purpose of screening, blood can be collected on farm and Noppe et al. (2008) previously reported a higher occurrence of steroid hormones within the blood due to the circulating action 
118 from anabolic tissues and metabolomic profiling has already revealed potential 119 biomarkers within the plasma collected (Graham et al. 2012).

120 Metabolomic fingerprinting has been promoted as a non-targeted approach 121 whereby the entire metabolite profile is compared to unveil markers which differ 122 between animal cohorts (Fiehn, 2002; Dettmer et al. 2007). The acquisition of such a vast amount of data requires both bioinformatic tools to generate models which can distinguish the disrupted homeostatic state due to exogenous drug administration and predictive techniques that assign acquired data to an assumed response (Antignac et al. 2011; Courant et al. 2014). Recent research incorporating the whole profile of blood metabolites to discriminate cattle exposed to growth promoting agents has been described (Regal et al. 2011; Dervilly-Pinel et al. 2012; Graham et al. 2012; Nzoughet et al. 2015a), yet progress towards applicable screening approaches is as yet unrealised. Metabolites contributing to differentiating profiles have been investigated (Riedmaier et al. 2009; Pinel et al. 2010; Dervilly-Pinel et al. 2012) but their reliability is often obscured by biological and environmental conditions and the specific relevance of metabolite profiles to individual growth promoter treatments is not clear.

The focus of the current study has centred on the detection of metabolomic and oestradiol compounds in bovine animals for meat enhancement purposes. encouraging lean meat production (Antignac et al. 2001; Cannizzo et al. 2011). The use of 140 oestradiol for growth promoting purposes is currently prohibited by the Scientific 141 Committee on Veterinary Measures relating to Public Health (SCVPH) (Directive, 2003), 
142 and whilst effective monitoring procedures have been established, it's availability outside 143 the EU is thought to contribute to a black market of illicit use (Courtheyn et al 2002; Regal 144 et al. 2012) with administrations difficult to distinguish from variable endogenous levels 145 in cattle (Regal et al. 2011). We for the first time unveil the bovine plasma metabolome 146 changes, detected by ultra-high performance liquid chromatography coupled to high 147 resolution mass spectrometry (UHPLC-HRMS), significant to the administration of 148 oestradiol, dexamethasone or prednisolone. The results illustrate the use of advanced 149 statistical models incorporating ions altered by various treatment types to predict growth 150 promoter exposure, whilst putative identifications highlight the possible underlying metabolite functions specific to administered compounds. 


\section{MATERIALS AND METHODS}

154

155

\subsection{Chemicals and reagents}

LC-MS grade methanol $(\mathrm{MeOH})$ and formic acid $(\mathrm{HCOOH})$ were purchased from Sigma Aldrich (UK). Leucine enkephalin (Leu-Enk) was sourced from Waters (UK) and ultra-pure water (18.2 $\mathrm{M} \Omega \mathrm{cm}^{-1}$ ) was generated in-house using a Millipore system (Millipore, USA).

\subsection{Experimental design and plasma sample collection}

Samples were obtained from an experimental treatment study using growth promoting regimes reflective of suspected on-farm practices conveyed in the literature (Courtheyn et al. 2002; Cannizzo et al. 2008; De Maria et al. 2009). Authorized by the Italian Ministry of Health and bioethics committee of the University of Turin, the study cohort consisted of twenty four male Charolais cattle aged 17-22 months old randomly assigned to four treatment groups: Group $\mathrm{O}(n=6)$ received $0.01 \mathrm{mg} / \mathrm{kg}$ intramuscular injection of $17 \beta$ oestradiol-3-benzoate (Sigma-Aldrich, Milan, Italy) weekly on day 12, 19, 26, 33 and 40; Group $D(n=6)$ were administered an oral dose of $0.7 \mathrm{mg} /$ day dexamethasone-21-sodium phosphate (Desashock Fort Dodge Animal Health, Bologna, Italy) for 40 days; Group P ( $n=6)$ were given $15 \mathrm{mg} /$ day prednisolone acetate orally (Novosterol, Ceva Vetem SpA, Milan, Italy) for 30 days; Group C $(n=6)$ were control untreated animals. All animals were kept in separate housing and fed a diet of silage, corn and hay alongside a commercial protein supplement and water. Blood was collected via the jugular vein on days $0,7,25$, 35, 43 and at slaughter (day 49) using EDTA tubes for plasma preparation (centrifugation at $2,000 \times g$ for $20 \mathrm{~min}$ ) which was stored at $-80^{\circ} \mathrm{C}$.

\subsection{Plasma sample preparation for metabolomic profiling}


177 Minimal sample preparation was carried out on twenty four plasma samples collected on 178 day 25 of the animal study to ensure intact metabolite coverage with samples 179 randomized during analysis to avoid bias in preparation. A volume of $100 \mu \mathrm{L}$ of plasma was centrifuged at $1,000 \times g$ for 5 mins and extraction conducted by addition of $400 \mu \mathrm{L}$ ice cold $\mathrm{MeOH}\left(<2{ }^{\circ} \mathrm{C}\right)$, vortexing briefly and holding on ice for 20 mins. Samples were subsequently centrifuged at an increased speed of $15,000 \times g$ for 10 mins to separate the proteinaceous pellet. The supernatant was removed and evaporated to dryness in a Savant ${ }^{\mathrm{TM}}$ SpeedVac ${ }^{\mathrm{TM}}$ concentrator (Thermo Scientific, USA) operating at $40^{\circ} \mathrm{C}$, and reconstituted in $50 \mu \mathrm{L}$ ultrapure water with 5 mins vortexing followed by filtering through a Costar ${ }^{\circledR}$ Spin-X $0.22 \mu \mathrm{m}$ tube filter (Sigma Aldrich, UK) under centrifugation at $15,000 \mathrm{x}$ $g, 4^{\circ} \mathrm{C}$ for 2 mins. $100 \mu \mathrm{L}$ from each of the plasma samples under investigation were pooled and similarly prepared for quality (QC) purposes. Filtered samples were stored at $80^{\circ} \mathrm{C}$ in a LCGC Certified Clear Glass $(12 \times 32 \mathrm{~mm}$ ) autosampler vial (Waters, UK) prior to UPLC-HRMS analysis.

\subsection{UHPLC-QTof-MS metabolomic plasma profiling}

Chromatographic separation was performed using an Acquity ${ }^{\mathrm{TM}}$ UPLC system (Waters, UK) comprising of a stainless steel Aquity UPLC ${ }^{\circledR}$ HSS T3 analytical column $(100 \times 2.1 \mathrm{~mm}$, particle size $1.8 \mu \mathrm{m}$ ) (Waters, UK). The column temperature was maintained at $45^{\circ} \mathrm{C}$ with gradient was set at $1 \%$ B for 2 mins increasing to $70 \%$ B, by 7 mins to $99 \%$ B at 16.25 mins, 
solvent was prepared with $\mathrm{H}_{2} \mathrm{O}: \mathrm{MeOH}(1: 1, v / v)$, the seal wash was made up of $\mathrm{H}_{2} \mathrm{O}: \mathrm{MeOH}(95: 5, \mathrm{v} / \mathrm{v})$ and the purge wash consisted of $\mathrm{HCOOH}: \mathrm{H}_{2} \mathrm{O}(1: 1000, v / v)$.

\subsection{System calibration and quality control checks}

A reference standard (Waters, UK) consisting of $2 \mathrm{ng} / \mu \mathrm{L}$ nine component mix of acetaminophen, caffeine, sulfaguanidine, sulfadimethoxine, Val-Tyr-Val, verapamil, terfenadine, Leu-Enk and reserpine, was injected prior to each run $(n=3)$ to ensure retention time and mass accuracy. The UHPLC-QTof-MS system was equilibrated with sodium formate at a flow rate of $5 \mu \mathrm{L} / \mathrm{min}$ with column equilibration via injection of ten replicates of pooled plasma prior to analysis and intermittent injections of pooled QC plasma throughout the run. Leu-Enk was introduced at $1 \mathrm{ng} / \mu \mathrm{L}$ in $\mathrm{H}_{2} \mathrm{O}: \mathrm{MeCN}: \mathrm{HCOOH}$ (50:50:0.1, v/v/v) to compensate for mass shift.

\subsection{Mass spectrometry data acquisition and processing}

The UHPLC system was coupled to a Xevo ${ }^{\circledR} \mathrm{G} 2$ Q-Tof mass spectrometer and controlled via v4.1 MassLynx ${ }^{\mathrm{TM}}$ software (both from Waters, UK). Q-Tof-MS data was acquired in resolution mode. Acquisition was conducted using positive electrospray ionization mode $(\mathrm{ESI}+)$ with the capillary voltage set at $1 \mathrm{kV}$ and the cone gas flow of $50 \mathrm{~L} / \mathrm{h}$. The source temperature was set at $120^{\circ} \mathrm{C}$ with $60 \mathrm{AU}$ offset and the desolvation gas set at $450^{\circ} \mathrm{C}$ with flow rate of $850 \mathrm{~L} / \mathrm{h}$. Nitrogen was employed as the desolvation and cone gases. Data was acquired in continuum mode using $\mathrm{MS}^{\mathrm{E}}$ with scan time 0.1 sec over 50-1200 Da under 4 $\mathrm{eV}$ low energy and a ramp of 20-35 eV at high energy. Lockmass calibration during data acquisition was set at capillary voltage $1.40 \mathrm{kV}$ and collision energy $20 \mathrm{eV}$ with dual point 
225 intervals with mass window $\pm 0.5 \mathrm{Da}$. UHPLC-HRMS raw data files were exported for pre226 processing into Progenesis $\mathrm{QI}^{\circledR}$ software (Waters, UK). Chromatograms were aligned to a 227 reference $\mathrm{QC}$ run and selected adducts included $[\mathrm{M}+\mathrm{H}]^{+},\left[\mathrm{M}+\mathrm{H}-\mathrm{H}_{2} \mathrm{O}\right]^{+},[\mathrm{M}+\mathrm{Na}]^{+},[\mathrm{M}+\mathrm{K}]^{+}$, $228\left[\mathrm{M}+\mathrm{H}-2 \mathrm{H}_{2} \mathrm{O}\right]^{+}$, and $\left[\mathrm{M}+\mathrm{CH}_{3} \mathrm{OH}+\mathrm{H}\right]^{+}$with $2.5 \mathrm{AU}$ filter. Peak picking was set to exclude ions 229 eluted before 0.5 mins (1\%) and after 14 mins (92\%) at $1 \%$ and $92 \%$ organic solution, 230 respectively. Deconvolution was applied to detect ions which may be formed from the 231 same compound. The raw data was normalized for all compounds and exported in .CSV format for further analysis reporting selected ions by their accurate mass and retention time pair (AMRTP). Ions which demonstrated relative standard deviation (RSD) greater than $30 \%$ in QC pools were discarded from analysis. An $80 \%$ rule was also applied to eliminate any ions which were not detected in more than $80 \%$ of the samples analysed; that is, where a zero value was obtained in more than $20 \%$ of the sample set analysed, it was considered spurious and excluded from the dataset.

2.7. Analysis of plasma metabolite ions discriminating between growth promoter treatment regimes

\subsubsection{Univariate statistics}

242 Acquired plasma metabolome datasets were first analysed using Excel 2010 (Microsoft Office, USA) for conventional statistical comparison of treated and untreated groups. Three technical replicates were averaged to provide a peak abundance of six animals per treatment group for the respective ions detected. Additionally a lower limit of 500 for the peak output was applied whereby ions showing average abundance $<500$ across the respective treatment groups were excluded as indistinguishable from background noise. 
group was tested for unequal variance via F-test against the control group. Significance of $p<0.05$ was then determined using a two-tailed student's $t$-test comparing the control

251 untreated group to each treated animal group, where type 2 was applied for homoscedastic variance $(F>0.05)$ and type 3 when heteroscedastic $(F<0.05)$. Those ions showing significant difference in abundance when compared to the control output were considered useful for further analysis.

\subsubsection{Multivariate statistics}

SIMCA version 13.0 (Umetrics, Sweden) was used for multivariate analysis of metabolomic profiles of plasma from various treatment groups to highlight discriminatory ions. The normalized value outputs from Progenesis $\mathrm{QI}^{\circledR}$ for each sample injection, inclusive of all metabolites ( $<30 \%$ RSD), were subject to pareto scaling and projections were made between control and respected treated animal sets. Principal Component Analysis (PCA) enabled unsupervised separation of the test samples against the QC injections to ensure quality control samples were clustered together and check that the technical replicate injections were similarly aligned. Test samples were assigned as either control or treated for subsequent supervised analysis via orthogonal partial least squares discriminant analysis (OPLS-DA). Having obtained good prediction $\left(Q^{2}\right)$ and separation $\left(R^{2}\right)$ via OPLS-DA, S-plot and variable importance of projection (VIP) plots were utilized to select those ions contributing most to the predictive components. Markers were selected based on having a VIP score greater than 1 and subsequent jack-knifed confidence intervals with coefficient (cvSE) less than the VIP score. These were reviewed via S-plot representing positive or negative correlation $p$ (corr) against covariance $p[1]$ with those

271 plotted on the outer edges of the graphical area ( $\mathrm{p}[\mathrm{corr}]>0.5)$ considered to have strong 
273 verifying their predictive ability with 100 rounds of permutation testing alongside cross-

274 validation via CV-ANOVA.

275

276

2.8. Metabolite identification

277 Selected AMRTPs were confirmed as peaks extractable from the raw chromatogram using MassLynx $^{\mathrm{TM}}$ and the theoretical elemental composition of the selected feature determined (Kind et al. 2007; Watson, 2013). Mass uncertainty was set at 5 mDa or 10 ppm for those ions with $\mathrm{MW} \leq 400 \mathrm{Da}$ or $>400 \mathrm{Da}$, respectively, and elements were restricted to $\mathrm{C}, \mathrm{H}, \mathrm{O}, \mathrm{N}, \mathrm{P}$ and $\mathrm{S}$. The mass of the parent compound was then searched against known databases (METLIN, HMDB, PubChem) to make putative identifications in consideration of the isotope pattern and subsequent charged state with adducts confirmed against the mass spectrometry adduct calculator provided by Fiehn Lab (http://fiehnlab.ucdavis.edu/). Biological contributions were determined from subsequent PubChem classification (NCBI, USA) and corresponding KEGG (Kanehisa Laboratories, Japan) and LIPID MAPS (www.lipidmaps.org) pathway analysis. 


\section{RESULTS AND DISCUSSION}

290

291

292

293

294

295

296

Metabolite markers specifically altered within the plasma of cattle in response to glucocorticoid and oestradiol treatment regimes were successfully reported using UHPLCHRMS metabolomics profiling.

\subsection{Assessment of plasma metabolome profile output}

A comparison of the profile of metabolites detected in bovine plasma following UHPLCHRMS analysis is displayed in Figure 1 with base peak ion chromatogram (BPI) obtained from MassLynx ${ }^{\mathrm{TM}}$ representing control, oestradiol, dexamethasone and prednisolone plasma metabolomes. Whilst it is not possible to discern obvious differences in the resulting plasma metabolome profile from the $\mathrm{BPI}$, it is anticipated that any minor deviations from the untreated state could reflect xenobiotic influence and respective chromatograms were subsequently analysed via Progenesis $\mathrm{Q}^{\circledR}$ software. This enabled automated alignment, peak picking and mining of the generated metabolome dataset. The plasma metabolomic profile of each sample injection $(n=72)$ was displayed as an ion intensity map and replicate injections were combined and matched across treatment groups for quality assurance. Resulting chromatograms conferred 3522 features detected across all runs, which were further deconvoluted to 3088 ions. Peak abundance was normalized and elimination of those ions displaying a RSD $>30 \%$ in QC injection lead to a reduction of the dataset to 1364 ions. Proceeding with the application of the $80 \%$ rule, additional falsities were omitted assembling a final list of 751 metabolites suitable for multivariate analysis.

\subsection{Metabolite fingerprint modelling via multivariate classification}


313 Unsupervised principal component analysis (PCA) was initially employed to compare the

314 metabolome profiles of test samples to the QC samples from the 3088 detected features

315 (Figure 2a). QC samples were tightly clustered demonstrating stability of the run and 316 individual test replicate injections were similarly aligned showing repeatability of the

317 platform performance. PCA was then used to ascertain if study groups could be classified

318 from an unsupervised prospective based on the 751 ions of interest (Figure 2b). However,

319 separation of control and treated profiles was not clearly distinguishable and

320 subsequently supervised separation was applied. An OPLS-DA model was constructed

321 from 751 variables and 63 observations based on 3 components with the control

322 untreated profile plotted against each treated metabolome profile (Figure 3a) and

323 demonstrated good fit based on $\%$ variation of the data set $\left(R^{2} X=0.907, R^{2} Y=0.978\right)$ with

324 potential to predict new data $\left(Q^{2}=0.916\right)$. Overfitting of the OPLS-DA dataset was

325 avoided by allocating principal components based on 7 rounds of cross-validation.

326 Furthermore, assessment of each treatment group to the control via OPLS-DA based on

327751 variables (Figure $3 b-d$ ), showed good separation and predictive ability of oestradiol

$328\left(R^{2} Y=0.993, Q^{2}=0.940\right)$, dexamethasone $\left(R^{2} Y=0.986, Q^{2}=0.943\right)$, or prednisolone $\left(R^{2} Y=\right.$

$\left.3290.890, \mathrm{Q}^{2}=0.723\right)$ plasma profiles. Interestingly, both glucocorticoid treatments

330 demonstrated similar patterns of separation from the untreated group yet distinctive

331 metabolome changes are further discussed.

\subsection{Analysis of selective ions contributing to separation}

The variables contributing most to the separation of untreated and treated profiles were assessed via the variable importance of projection (VIP) plot which showed 135 ions with 
337 for each treatment type as shown in Figure 4, revealed 56 ions relevant to oestradiol

338 treatment, 45 ions discriminating dexamethasone treatment and 58 significant to 339 prednisolone treatment profiles. Shared and unique structure (SUS) plots were used to 340 illustrate ions comparable across the treated profiles (Figure 5) culminating in 99 features 341 of interest.

\subsection{Assessment of the predictive ability of the multivariate model}

The selected ions ( $n=99$ ) were used to generate a new OPLS-DA model (Figure 6a) capable of discriminating treated from untreated metabolome profiles. It is anticipated that a model could indicate the use of either oestradiol, dexamethasone or prednisolone. The predictive ability of the model was tested by computing 100 rounds of iteration testing. This automatically assigned permuted points to the left with new observations lower than the original untreated on the right (see figure $6 \mathrm{~b}$ ). The regression showed sufficient separation of newly generated observations demonstrating good prediction with Q2 below the X-axis $(-0.62)$. The model was further tested by cross validation based on $2 / 3$ of the dataset used to correctly assign the remaining $1 / 3$. Assessment of the significance of the model by CV-ANOVA based on F-distribution of the prediction error with one degree of freedom showed significant regression $(p<0.01)$ with $p$-value of $1.73 \times 10^{-18}$. Similar assessment of the separate treatment group models for oestradiol, dexamethasone or prednisolone prediction showed significant classification $(p<0.01)$ from CV-ANOVA.

\subsection{Statistical analysis of discriminatory ions}

359 Further assessment of the metabolic changes found 32 features at an increased level 
compound administrations (Table $1 \mathrm{a}$ and $1 \mathrm{~b}$ ), respectively. Notably ten ions were commonly increased in all treatment groups, whilst seven ions were found to be depressed. Finally, comparison of the metabolome profile of each treatment group to the control group via student's $t$-test analysis revealed 24 ions which were significantly $(p<0.05)$ altered across the biological replicates (Table 2$)$ and were identified as possible biomarkers of the respective growth promoter treatments.

\subsection{Assignment of putative identification of ions of interest}

The use of both high- and low-collision energies during the mass spectrometry data acquisition provided fragment rich spectra for putative identifications of the features of interest. The spectrum of each ion was extracted from a representative chromatographic peak highlighting the precursor ion. Examination of the isotope ratio confirmed the charge state as single $(+)$, double $(++)$ or triple $(+++)$ in deduction of the visible adduct

374 formation. The putative mass was matched against the fragmented spectrum and resulting identities of the 24 metabolites of interest (Table 2). The maximum mass difference observed was $12 \mathrm{mDa}$ with exception of AMRTP 4.41 _ $344.8505 \mathrm{~m} / \mathrm{z}$, 5.80_741.3737m/z and 6.07_618.6912 $\mathrm{m} / \mathrm{z}$ whose mass differences were $36.1,16.6$ and 16.4, respectively. However, these adducts represent larger compounds where additional fragments available from function 2 data were incorporated to check tentative assignments.

\subsection{Biological classification of identified marker metabolites}

383 Putative identifications reveal the majority of functional roles relating to lipid metabolism 
metabolism and additional roles such as acylcarnitines, dipeptides, eicosanoids and

vitamin or steroid derivatives. These findings complement biomarker candidates

previously highlighted by proteomic investigation (Kinkead et al. 2015) implicating anabolic interactions with apolipoproteins and vitamin-D-binding proteins as responsible

for the underlying biological mechanisms. An example of the expression levels of specific markers displayed by the differing treatment groups is shown in Figure 8 and are further discussed below.

\subsubsection{Phospholipids}

Resulting plasma metabolite identifications indicate cytidine diphosphate diacylglycerol (CDP-DG) and other glycerophospholipids including those bound to glycerol (PG, DG), inositol (PI), choline (PC) and ethanolamine (PE) as significantly preturbed by growth promoter treatment regimes. They are members of the G-protein coupled receptor family previously implicated as responsive to steroid influence (Prossnitz et al. 2008) ) and significantly altered by growth promoter treatment (Nzoughet et al. 2015b).. These glycerophospholipids are known to play an important role in the generation of triacylglycerides from glycerol-3-phosphate by acting on phosphatidic acid and contributing metabolic functions (Stapleton et al. 2011). However plasma levels of PG $(18: 4(6 Z, 9 Z, 12 Z, 15 Z) / 12: 0)$ were also shown to be reduced by growth promoter treatment in this study as it is known to be cleaved to form diacylglycerol. The fluctuating levels are probably due to the relative transformation state but may also be dependent on the agent administered. Others (Kitson et al. 2013) found increased plasma phospholipid levels in rats supplemented with $17 \beta$-oestradiol whilst Nzoughet et al.

407 (2015b) reported a decrease in PG, PI, PA, PE, PC upon administration of trenbolone 
triacylglycerides and subsequent metabolic functions (Stapleton et al. 2011). Additionally LysoPC was notably increased in the study and is formed in plasma by a specific enzyme system, lecithin-cholesterol acyltransferase (LCAT) which catalyzes the transfer of fatty acids to free cholesterol bound to high/low density lipoproteins (H/LDL). This complements previous proteomic analysis showing increased levels of apolipoproteins A1 and AIV (Kinkead et al. 2015).

\subsubsection{Sphingolipids}

Treatment of cattle with oestradiol, dexamethasone or prednisolone resulted in a dramatic increase in the level of plasma sphingolipids in this study. Sphingolipids have been shown to modulate the steroid hormone biosynthetic pathway at multiple levels, including gene expression, steroidogenic activity and act as second messengers in signalling cascades (Lucki, Sewer 2008; Sabourdy et al. 2008). Studies have shown demonstrable increased levels associated with insulin resistance and contributing metabolic disorders where glucocorticoids are known to have large and specific effects on sphingolipid expression (Holland, Summers, 2008). Specifically, ganglioside GT1b, 6Galß1, Gala1-3, GM3 were increased most by prednisolone administration in this study with observable fold change differences ranging from 3-11 times the peak output from the untreated plasma metabolite profile. These gangliosides make up the cell membrane and are involved in signal transduction mediated by the liver contributing to lipoprotein sialylation and cholesterol efflux through inhibition of glycerophospholipids (Millar, 2001, Subbaiah et al. 1993). Previous reports indicate dysregulation of sphingolipids having 431 profound effects on glycerophospholipid expression in plasma (Rodrigues-Cuenca et al. 432 2017). Sphingolipids can be found in all tissues and biofluids since they contribute largely 
433 to the immune responseg (Garcia-Barros et al. 2015). Furthermore, gangliosides are

434 known to inhibit pro-inflammatory signals (Miklavcic et al. 2012) which may explain why

435 they are increased herein more so by prednisolone due to its anti-inflammatory action.)

436

$437 \quad$ 3.7.3 Fatty acid synthesis

438 An increase in 6-oxocyclohex-1-ene-1-carboxyl-CoA was displayed across all treatments in 439 this study and has not previously been reported relevant to the bovine growth promoter 440 response. We know acyl-Coenzyme A plays a key role in fatty acid metabolism as well as 441 lipid synthesis and expression levels are altered by anabolic influence for energy 442 production (Zhao et al. 2016; Pietrocola et al. 2015). Whilst oestradiol administration resulted in the greatest increase in CoA in this study, the levels expressed were shown to 444 be most significantly evident in dexamethasone treated animals with lower levels displayed by the prednisolone treatment group. Other studies have found increased expression of the CoA gene after administration with prohormone 447 dehydroepiandrosterone for the purpose of growth promotion in cattle (Rijk et al. 2010). Acyl CoA is also influenced by glucose homeostasis with increased expression resulting in high uptake of fatty acids in adipose tissue and increased triacylglycerol synthesis (Zhao et al. 2016). Fatty acid metabolites $N$-stearoyl tyrosine and hypusine were notably decreased after growth promoter treatment hereinand may reflect the feedback redirection of acyl thioesters from plasma via CoA binding proteins (Faergeman, Knudsen 1997). 
456 The level of acylcarnitines in the plasma metabolome of growth promoter treated animals

457 was found to be reduced in comparison to that of untreated animals. Specifically, 458 hepatonylcarnitine was reduced by up to $73 \%$ and found to be significantly depressed by 459 oestradiol treatment, whilst other stearidonyl carnitine and 12-hydroxy-12460 octadecanoylcarnitine were found to be significantly reduced within the dexamethasone 461 metabolome profile. Acylcarnitines are predominantely derived from $\beta$-oxidation of fatty 462 acids and increased levels are known to contribute to fatty acid metabolism to meet energy demands whilst decreased utilization of fatty acids would lead to decreased acylcarnitine expression (Hoppel, 2003; Thompson et al. 2012).The regulation of acylcarnitines is interestingly mediated by $\operatorname{CoA}$ with accumulated response to inflammation, insulin sensitivity and other signal transduction events (McCoin et al. 2015).

\subsubsection{Eicosanoids}

An increase in the level of an eicosanoid was observed across all growth promoter treated plasma profiles. Eicosanoids are synthesised from arachidonic acid and are involved in autocrine and paracrine response (Nebert, Russel, 2002) operated via G protein receptors through lipid signalling pathways (Funk, 2001). They have not previously been implicated in the bovine growth promoter response but are known to be anti-inflammatory mediators (Salmon, Higgs 1987) and specifically leukotriene E3 was significant to prednisolone administration.

\subsubsection{Additional metabolites}

478 Interestingly, the dipeptide tryptophyl-proline was shown to be increased in the plasma of cattle exposed to growth promoter treatments in this study alongside isoleucyl- 
tryptophan which was significant to the dexamethasone treatment group. Regal et al.

481 (2014) also reported an increase in pyroglutamyl-phenylalaninedipeptide as a biomarker 482 of oestradiol administration. Such increases may be attributed to roles in protein metabolism but their specific action in the growth promoter response remains unclear.

484 Other metabolites of interest were found to be significantly reduced in response to dexamethasone treatment including a bile acid (Chenodeoxycholic acid glycine conjugate), vitamin D3 derivative (3'-O-Aminopropyl-25-hydroxyvitamin D3) and steroid metabolite (1'H-5alpha-Cholest-2-eno[3,2-b]indole), which is indicative of additional biological pathways affected by corticosteroid metabolism. Moreover, an increase in 3methylene-indolenine within oestradiol and prednisolone treatment metabolome profiles is not clear since it functions as a catalyst in the formation of reactive intermediates from pneumotoxic chemicals via cytochrome P450. An additional marker ion $\left(6.80 \_989.5636 \mathrm{~m} / \mathrm{z}\right)$ shown to be significantly increased in response to oestradiol treatment could not be identified from available metabolite databases.

\section{Conclusions}

Given the many issues which compromise the effective and sensitive monitoring of illegal growth promoter use in food production, it is clear that new strategies are required to more confidently determine cases of anabolic exposure that do not solely focus on concentration levels of drugs or their metabolites which can be eliminated rapidly or are autogenously present. The work herein demonstrates the capability of metabolomic screening methods to identify bovine animals subjected to various types of growth promoting treatment regimes. This is the first investigation of alterations to the metabolome detectable within plasma relevant to prednisolone, dexamethasone or 

oestradiol administrations, with 58,45 and 56 ions observed to be significantly altered in response to growth promoter treatments. Predictive modelling was shown to 506 successfully discriminate between the metabolome profiles of plasma from treated and 507 untreated animals based on 99 perturbed metabolite ions. Putative identification of 508 specific metabolites enables the development of candidate markers significant to oestradiol, dexamethasone or prednisolone administration. These were mostly

510 attributed to sphingolipid and glycerophospholipid pathways relevant to fatty acid 511 synthesis with implications on cholesterol transport, glycolysis and immune responses.

512 The differing responses relative to the level of drug exposure is yet to be determined but 513 it is anticipated that further development of these gangliosides, lipoproteins, Co-enzyme 514 A, acylcarnitines and eicosanoids into rapid onsite screening tools could detect cases of 515 drug misuse prior to confirmatory analysis.

\section{ACKNOWLEDGEMENTS}

519 Queen's University Belfast gratefully acknowledges the financial sponsorship of Safefood and the UK Government Department for Employment and Learning, Northern Ireland (DELNI). The research was conducted within the Advanced ASSET Centre under good laboratory practice with no conflict of interest imposed. 


\section{REFERENCES}

525 Antignac, J. P., Courant, F., Pinel, G., Bichon, E., Monteau, F., Elliott, C., Le Bizec, B. (2011).

526 Mass spectrometry-based metabolomics applied to the chemical safety of food. Trends in 527 Analytical Chemistry. 30 (2), 292-301.

528 Antignac, J. P., Le Bizec, B., Monteau, F., Poulain, F., Andre, F. (2001). Multi-residue extraction-purification procedure for corticosteroids in biological samples for efficient control of their misuse in livestock production. Journal of Chromatography B: Biomedical Sciences and Applications, 757 (1), 11-19.

Arioli, F., Fidani, M., Casati, A., Fracchiolla, M.L., Pompa, G. (2010). Investigation on possible transformations of cortisol, cortisone and cortisol glucuronide in bovine faecal matter using liquid chromatography-mass spectrometry. Steroids, 75 (4), 350-4.

535 Cannizzo, F. T., Capra, P., Divari, S., Ciccotelli, V., Biolatti, B., Vincenti, M. (2011). Effects of 536 low-dose dexamethasone and prednisolone long term administration in beef calf: 537 chemical and morphological investigation. Analytica chimica acta. 700 (1), 95-104.

538 Cannizzo, F.T., Miniscalco, B., Riondato, F., Bollo, E., Barbarino, G., Giorgi, P., Mazzini, C., 539 Biolatti, B. (2008). Effects of anabolic and therapeutic doses of dexamethasone on thymus 540 morphology and apoptosis in veal calves. Veterinary Record: Journal of the British 541 Veterinary Association, 163 (15), 448-452

542 Chiesa, L.M., Nobile, M., Biolatti, B., Pavlovic, R., Panseri, S., Cannizzo, F.T., Arioli, F. 543 (2016). Detection of selected corticosteroids and anabolic steroids in calf milk replacers 
544 by liquid chromatography-electrospray ionisation-Tandem mass ectrometry. Food 545 Control, 61, 196-203.

546 Courant, F., Antignac, J. P., Dervilly-Pinel, G., Le Bizec, B. (2014). Basics of mass 547 spectrometry based metabolomics. Proteomics, 14 (21-22), 2369-2388.

548 Courant F, Pinel G, Bichon E, Monteau F, Antignac JP, Le Bizec B. (2009). Development of a 549 metabolomic approach based on liquid chromatography-high resolution mass 550 spectrometry to screen for clenbuterol abuse in calves. Analyst, 134 (8), 1637-46.

551 Courtheyn, D., Le Bizec, B., Brambilla, G., De Brabander, H.F., Cobbaert, E., Van de Wiele, 552 M., Vercammen, J., De Wasch, K. (2002). Recent developments in the use and abuse of 553 growth promoters. Analytica Chimica Acta, 473 (1), 71-82.

554 De Maria, R., De Maria, R., Divari, S., Goria, M., Bollo, E., Cannizzo, F.T., Olivero, M., 555 Barbarino, G., Biolatti, B. (2009). 17ß-oestradiol-induced gene expression in cattle 556 prostate: biomarkers to detect illegal use of growth promoters. Veterinary Record, 164, $557 \quad 459-464$.

558 Department of Agriculture Food and the Marine (DAFM). National Residue Plan Report. 559 (2015).

560 http://www.agriculture.gov.ie/animalhealthwelfare/veterinarymedicinesresidues/ 561 Accessed: 01.11.16.

562 Dervilly-Pinel, G., Courant, F., Chéreau, S., Royer, A.L., Boyard-Kieken, F., Antignac, J.P., 563 Monteau, F., Le Bizec, B. (2012). Metabolomics in food analysis: application to the control 564 of forbidden substances. Drug testing and analysis, 4 (1), 59-69. 
565 Dervilly-Pinel G, Weigel S, Lommen A, Chereau S, Rambaud L, Essers M, Antignac JP, 566 Nielen MW, Le Bizec B. (2011). Assessment of two complementary liquid chromatography 567 coupled to high resolution mass spectrometry metabolomics strategies for the screening 568 of anabolic steroid treatment in calves. Analytica Chimica Acta, 700 (1), 144-54.

569 Dettmer, K., Aronov, P. A., Hammock, B. D. (2007). Mass spectrometry-based 570 metabolomics. Mass spectrometry reviews, 26 (1), 51-78.

571 Doué, M., Dervilly-Pinel, G., Cesbron, N., Stefani, A., Moro, L., Biancotto, G., Le Bizec, B. 572 (2015). Clinical biochemical and hormonal profiling in plasma: a promising strategy to 573 predict growth hormone abuse in cattle. Analytical and bioanalytical chemistry, 407 (15), $574 \quad 4343-4349$.

575 EU Commission (2003). Commission Directive No 2003/74/EC of 22 September 2003 576 amending Council Directive 96/22/EC concerning the prohibition on the use in 577 stockfarming of certain substances having a hormonal or thyrostatic action and of beta578 agonists. Official Journal of the European Union, L262, 17-21

579 EU Commission (1996). Commission Directive 96/23/EC of 29 April 1996 on measures to 580 monitor certain substances and residues thereof in live animals and animal products and 581 repealing Directives 85/358/EEC and 86/469/EEC and Decisions 89/187/EEC and 582 91/664/EEC. Official Journal of the European Communities, L125/10.

583 European Food Safety Authority (EFSA). Report for 2012 on the results from the 584 monitoring of veterinary medicinal product residues and other substances in live animals 585 and animal products. (2013). 
586 https://ec.europa.eu/food/sites/food/files/safety/docs/cs_vet-med-

587 residues_workdoc_2012_en.pdf Accessed 01.11.16

588 European Parliament and Council (2002). Regulation 2002/178/EC of 28 January 2002, 589 laying down the general principles and requirements of food law, establishing the 590 European Food Safety Authority and laying down procedures in matters of food safety. 591 Official Journal of the European Union, 31, 1-24.

592 Faergeman, N.J. and Knudsen, J., (1997). Role of long-chain fatty acyl-CoA esters in the 593 regulation of metabolism and in cell signalling. Biochemical Journal, 323(1), 1-12.

594 Fiehn, O. (2002). Metabolomics-the link between genotypes and phenotypes. Plant 595 molecular biology, 48 (1-2), 155-171.

596 Funk, C.D., 2001. Prostaglandins and leukotrienes: advances in eicosanoid biology. 597 science, 294(5548), pp.1871-1875.

598 García-Barros, M., Coant, N., Snider, A.J. (2015). Sphingolipids in Intestinal Inflammation 599 and Tumorigenesis. Intestinal Tumorigenesis, 257-286.

600 Ginkel, L.A., Sterk, S.S. (2016). A view on the analytical design of future risk based residue 601 control. Drug Testing and Analysis, 8 (5-6), 521-524

602 Graham, S.F., Ruiz-Aracama, A., Lommen, A., Cannizzo, F.T., Biolatti, B., Elliott, C.T., 603 Mooney, M.H. (2012). Use of NMR metabolomic plasma profiling methodologies to 604 identify illicit growth-promoting administrations. Analytical and bioanalytical chemistry, 605 $403(2), 573-582$. 
606 Holland, W.L., Summers, S.A. (2008). Sphingolipids, insulin resistance, and metabolic 607 disease: new insights from in vivo manipulation of sphingolipid metabolism. Endocrine 608 reviews, 4, 381-402.

609 Hoppel, C. (2003). The role of carnitine in normal and altered fatty acid metabolism. 610 American Journal of Kidney Diseases, 41, S4-S12.

611 Imbimbo, P., Castigliego, L., Armani, A., Biolatti, B., Cannizzo, F.T., Gianfaldoni, D., Guidi, 612 A. (2012). A histologic study on growth promoter target organs of slaughtered beef in 613 Molise region (Italy). Journal of Veterinary Medical Science, 74 (10), 1253-1259.

614 Jacob, C. C., Dervilly-Pinel, G., Biancotto, G., Monteau F., Le Bizec, B. (2015). Global urine 615 fingerprinting by LC-ESI (+)-HRMS for better characterization of metabolic pathway 616 disruption upon anabolic practices in bovine. Metabolomics, 11 (1), 184-97.

617 Janssens, G., Mangelinckx, S., Courtheyn, D., Prévost, S., De Poorter, G., De Kimpe, N., Le 618 Bizec, B. (2013). Application of gas chromatography-mass 619 spectrometry/combustion/isotope ratio mass spectrometry (GC-MS/C/IRMS) to detect 620 the abuse of $17 \beta$-estradiol in cattle. Journal of agricultural and food chemistry, 61 (30), $621 \quad 7242-7249$.

622 Kind, T., Fiehn, O. (2007). Seven golden rules for heuristic filtering of molecular formulas 623 obtained by accurate mass spectrometry. BMC bioinformatics, 8 (105), 1-20

624 Kinkead, R.A., Elliott, C.T., Cannizzo, F.T., Biolatti, B., Mooney, M.H. (2015). Proteomic 625 identification of plasma proteins as markers of growth promoter abuse in cattle. 626 Analytical and bioanalytical chemistry, 407 (15).4495-4507. 
627 Kitson, A.P., Marks, K.A., Shaw, B., Mutch, D.M., Stark, K.D. (2013). Treatment of 628 ovariectomized rats with $17 \beta$-estradiol increases hepatic delta- 6 desaturase enzyme 629 expression and docosahexaenoic acid levels in hepatic and plasma phospholipids. 630 Prostaglandins, Leukotrienes and Essential Fatty Acids, 89 (2), 81-8.

631 Leporati, M., Abete, M.C., Vincenti, M., Ferro G.L., Ostorero, F., Gili, M. (2015). Illicit 632 administration of estradiol in cattle: case report. Journal of Veterinary Pharmacology and 633 Therapeutics, 38, 115-6.

634 Lucki, N.C., Sewer, M.B. (2008). Multiple roles for sphingolipids in steroid hormone 635 biosynthesis. Lipids in Health and Disease, 387-412.

Marin, A., Pozza, G., Gottardo, F., Moro, L., Stefani, A., Cozzi, G., Brscic, M., Andrighetto, 637 I., Ravarotto, L. (2008). Administration of dexamethasone per os in finishing bulls. II. 638 Effects on blood parameters used as indicators of animal welfare. Animal, 2 (7), 10806391086.

640 McCoin, C.S., Knotts, T.A. and Adams, S.H., 2015. Acylcarnitines-old actors auditioning 641 for new roles in metabolic physiology. Nature reviews. Endocrinology, 11(10), 617-636.

642 Miklavcic, J.J., Schnabl, K.L., Mazurak, V.C., Thomson, A.B.R. and Clandinin, M.T., (2012). 643 Dietary ganglioside reduces proinflammatory signaling in the intestine. Journal of 644 nutrition and metabolism, 1-8.

645 Mooney, M., Situ, C., Cacciatore, G., Hutchinson, T., Elliott, C., Bergwerff, A. (2008). 646 Plasma biomarker profiling in the detection of growth promoter use in calves. Biomarker, $64713(3), 246-256$. 
648 Mooney, M.H., Elliott, C.T., Le Bizec, B. (2009). Combining biomarker screening and mass649 spectrometric analysis to detect hormone abuse in cattle. Trends in Analytical Chemistry, $65028(6), 665-675$.

651 Nebbia, C., Urbani, A., Carletti, M., Gardini, G., Balbo, A., Bertarelli, D., Girolami, F. (2011).

652 Novel strategies for tracing the exposure of meat cattle to illegal growth-promoters. The 653 Veterinary Journal, 189 (1), 34-42.

654 Nebert, D.W., Russell, D.W. (2002). Clinical importance of the cytochromes P450. The 655 Lancet, 360 (9340), 1155-1162.

656 Nzoughet, J.J.K., Dervilly-Pinel, G., Chéreau, S., Biancotto, G., Monteau, F., Elliott, C.T., Le 657 Bizec, B. (2015a). First insights into serum metabolomics of trenbolone/estradiol 658 implanted bovines, screening model to predict hormone-treated and control animals' 659 status. Metabolomics, 11 (5), 1184-96.

660 Nzoughet, J.K., Gallart-Ayala, H., Biancotto, G., Hennig, K., Dervilly-Pinel, G., Le Bizec, B. 661 (2015b). Hydrophilic interaction (HILIC) and reverse phase liquid chromatography (RPLC)662 high resolution MS for characterizing lipids profile disruption in serum of anabolic 663 implanted bovines. Metabolomics, 11 (6), 1884-1895.

664 Pietrocola, F., Galluzzi, L., Bravo-San Pedro, J.M, Madeo, F., Kroemer, G. (2015). Acetyl 665 coenzyme A: a central metabolite and second messenger. Cell metabolism, 21 (6), 805666 821. 
Pinel, G., Weigel, S., Antignac, J. P., Mooney, M. H., Elliott, C., Nielen, M. W. F., Le Bizec, B. 668 (2010). Targeted and untargeted profiling of biological fluids to screen for anabolic 669 practices in cattle. Trends in Analytical Chemistry, 29 (11), 1269-1280.

670 Pompa, G., Arioli, F., Casati, A., Fidani, M., Bertocchi, L., Dusi, G. (2011). Investigation of 671 the origin of prednisolone in cow urine. Steroids, 76 (1), 104-10.

672 Prossnitz, E. R., Arterburn, J. B., Smith, H. O., Oprea, T. I., Sklar, L. A., Hathaway, H. J. 673 (2008). Estrogen signaling through the transmembrane $G$ protein-coupled receptor 674 GPR30. Annual Review of Physiology, 70, 165-190.

675 Regal, P., Blokland, M.H., Fente, C.A., Sterk, S.S., Cepeda, A., van Ginkel, L.A. Evaluation of 676 the Discriminative Potential of a Novel Biomarker for Estradiol Treatments in Bovine 677 Animals. Journal of agricultural and food chemistry. 2014, 63, 1, 370-378.

678 Regal, P., Alberto, C., Fente, C.A. (2012). Natural hormones in food-producing animals: 679 legal measurements and analytical implications. Food Production-Approaches, Challenges 680 and Tasks, 1, 205-230.

Regal, P., Nebot, C., Díaz-Bao, M., Barreiro, R., Cepeda, A., Fente, C. (2011). Disturbance in sex-steroid serum profiles of cattle in response to exogenous estradiol: A screening approach to detect forbidden treatments. Steroids, 76 (4), 365-375.

685 for biomarker development to trace functions of anabolic agents. Journal of 686 Chromatography A. 1216 (46), 8192-8199. 
Rijk., J.C., Lommen A., Essers M.L., Groot, M.J., Van Hende, J.M., Doeswijk, T.G., Nielen,

688

689

690

691

692

693

694

695

696

697

698

699

700

701

702

703

704

705

706

707

M.W. (2009). Metabolomics approach to anabolic steroid urine profiling of bovines treated with prohormones. Analytical Chemistry, 81 (16), 6879-88.

Rijk, J.C., Peijnenburg, A.A., Hendriksen, P.J., Van Hende, J.M., Groot, M.J., Nielen, M.W. (2010). Feasibility of a liver transcriptomics approach to assess bovine treatment with the prohormone dehydroepiandrosterone (DHEA). BMC veterinary research, 6(1),44-53.

Rodriguez-Cuenca, S., Pellegrinelli, V., Campbell, M., Oresic, M., Vidal-Puig, A. (2017). Sphingolipids and glycerophospholipids-The "ying and yang" of lipotoxicity in metabolic diseases. Progress in lipid research, 66, 14-29.

Ronquillo, M.G., Hernandez, J.C. (2017) Antibiotic and synthetic growth promoters in animal diets: Review of impact and analytical methods. Food Control, 28 (72), 255-67

Sabourdy, F., Kedjouar, B., Sorli, S.C., Colié, S., Milhas, D., Salma, Y. and Levade, T. (2008). Functions of sphingolipid metabolism in mammals-lessons from genetic defects. Biochimica et Biophysica Acta (BBA)-Molecular and Cell Biology of Lipids, 1781 (4), 145183.

Salmon, J.A., Higgs, G.A. (1987). Prostaglandins and leukotrienes as inflammatory mediators. British medical bulletin, 43(2), 285-296.

Stapleton, C.M., Mashek, D.G., Wang, S., Nagle, C.A., Cline, G.W., Thuillier, P., Leesnitzer, L.M., Li, L.O., Stimmel, J.B., Shulman, G.I., Coleman, R.A. (2011). Lysophosphatidic acid activates peroxisome proliferator activated receptor- $\gamma$ in $\mathrm{CHO}$ cells that over-express glycerol 3-phosphate acyltransferase-1. PlusOne. 6, 4 
Sterk, S., Blokland, M., De Rijke, E., Van Ginkel, L. (2014) EURL Reflection paper: Natural growth promoting substances in biological samples. Research Report RIKILT, 1-68.

Stolker, A.A.M, Brinkman, U.T. (2005). Analytical strategies for residue analysis of veterinary drugs and growth-promoting agents in food-producing animals-a review. Journal of Chromatography A, 1067 (1), 15-53.

Subbaiah, P.V., Liu, M.I.N.G. (1993). Role of sphingomyelin in the regulation of cholesterol esterification in the plasma lipoproteins. Inhibition of lecithin-cholesterol acyltransferase reaction. Journal of Biological Chemistry, 268 (27), 20156-20163.

Thompson, D.K., Sloane, R., Bain, J.R., Stevens, R.D., Newgard, C.B., Pieper, C.F., Kraus, V.B. (2012). Daily variation of serum acylcarnitines and amino acids. Metabolomics, 8 (4), $556-565$.

Vanhaecke, L., Antignac, J.P., Courtheyn, D., Le Bizec, B., De Brabander, H. (2011). Elimination kinetics of dexamethasone in bovine urine, hair and feces following single administration of dexamethasone acetate and phosphate esters. Steroids, 76 (1), 111117.

Watson, D.G. (2013). A rough guide to metabolite identification using high resolution liquid chromatography mass spectrometry in metabolomic profiling in metazoans. Computational and structural biotechnology journal, 4 (5), 1-10.

Zhao, Z.D., Zan, L.S., Li, A.N., Cheng, G., Li, S.J., Zhang, Y.R., Wang, X.Y., Zhang, Y.Y. (2016). Characterization of the promoter region of the bovine long-chain acyl-CoA synthetase 1 gene: Roles of E2F1, Sp1, KLF15, and E2F4. Scientific reports, 6, 19661. 
METABOLOME - from A) control, B) oestradiol, C) dexamethasone, D) prednisolone obtained from UHPLC-HRMS profiling in positive electrospray ionization mode across an increasing methanol gradient.

734

Figure 2. MULTIVARIATE DATA ANALYSIS OF METABOLITE PROFILES OF PLASMA FROM

PCA SCORES PLOT - of A) unsupervised separation of QC vs test data based on 3088 detected features; B) unsupervised separation of control from treated plasma metabolite profiles based on 751 ions of interest.

Figure 3. OPLS-DA CLASSIFICATION OF FEATURES $(n=751)$ ACQUIRED FROM PLASMA METABOLOME PROFILES - of A) untreated vs treated, B) untreated vs oestradiol, C) untreated vs dexamethasone, D) untreated vs prednisolone. Data was previously subjected to pareto scaling and separation shown is based on the first two components.

Figure 4. VIP PLOT OF CONTRIBUTING VARIABLES - highlighted from the OPLS-DA model. 135 ions demonstrating $\mathrm{VIP}>1$ and $\mathrm{cVSE}<\mathrm{VIP}$ were selected for further analysis as potential marker metabolites.

Figure 5. CONSTRUCTED S-PLOT OF FEATURES $(n=751)$ DETECTED FROM BOVINE PLASMA GENERATED BY OPLS-DA MODEL - comparing control untreated to A) oestradiol B)

751 dexamethasone C) prednisolone profiles. Ions highlighted red possess VIP $>1$ and demonstrate strong discriminatory power with $p[1]>0.05$ and $p(\operatorname{corr}[1])>0.1$. The 
positively correlated features are upregulated whilst negative features correspond to

754 down regulation in the treated state.

755

756

Figure 6. SUS PLOT OF THE TREATED PROFILES - separating control from oestradiol (M70),

757 dexamethasone (M69), prednisolone (M71) highlighting ions of interest as previously

758 selected from OPLS-DA models. Comparison of markers between A) oestradiol to

759 dexamethasone, B) dexamethasone to prednisolone, and C) oestradiol to prednisolone.

760 The variables lying across the diagonal are shared across the treatment types whereas the

761 outer boxes reveal those markers specific to the treatment profile where red-outlined box

762 denotes those specific to the $y$-axis model and the blue-outlined box denotes those

763 relevant to the $\mathrm{x}$ axis model. The number of commonly altered ions are depicted in D) a

764 venn diagram based on 99 ions of interest.

765

766 Figure 7. CLASSIFICATION OF SIGNIFICANT MARKERS - Elucidation of the biological

767 contribution of the 24 metabolites identified show over a third are relevant to lipids of

768 which function as either phospholipids or sphingolipids. Another third function as fatty

769 acyl or acyl carnitines, with the remaining metabolites involved in cell signalling and

770 metabolism, and only one metabolite remained unidentifiable. 
772 Table 1a RESULTING IONS OF INTEREST - found at increased levels in treated animals

773 compared to non-treated. Represented by AMRTP showing the average peak output 774 within the control untreated group and relative fold change $>1.5$ in red alongside the VIP 775 score and $p$-value determined from student's $t$-test $(n=6)$ highlighted in green as significant $(<0.05)$. Ten ions are shown commonly upregulated across all treatment types.

Table 1b RESULTING IONS OF INTEREST - found at decreased levels in treated animals compared to non-treated. Represented by AMRTP showing the average peak output within the control untreated group and relative fold change $<0.5$ in yellow alongside the VIP score and $p$-value determined from student's $t$-test $(n=6)$ highlighted in green as significant $(<0.05)$. Seven ions commonly decreased by all treatment types.

Table 2 PUTATIVE IDENTIFICATION OF METABOLITES - 24 plasma metabolites shown to be cumulatively increased or decreased across the treatment profiles in comparison to control untreated $(p<0.05)$, were assigned identifications by accurate mass based on the isotope charge $(+,++,+++)$ matching the formed adduct. Elemental composition analysis predicted chemical formulae and corresponding assignments show a mass difference $<11$ mDa with exception of * ions which were confirmed by additional fragments present. 
FIGURE 1
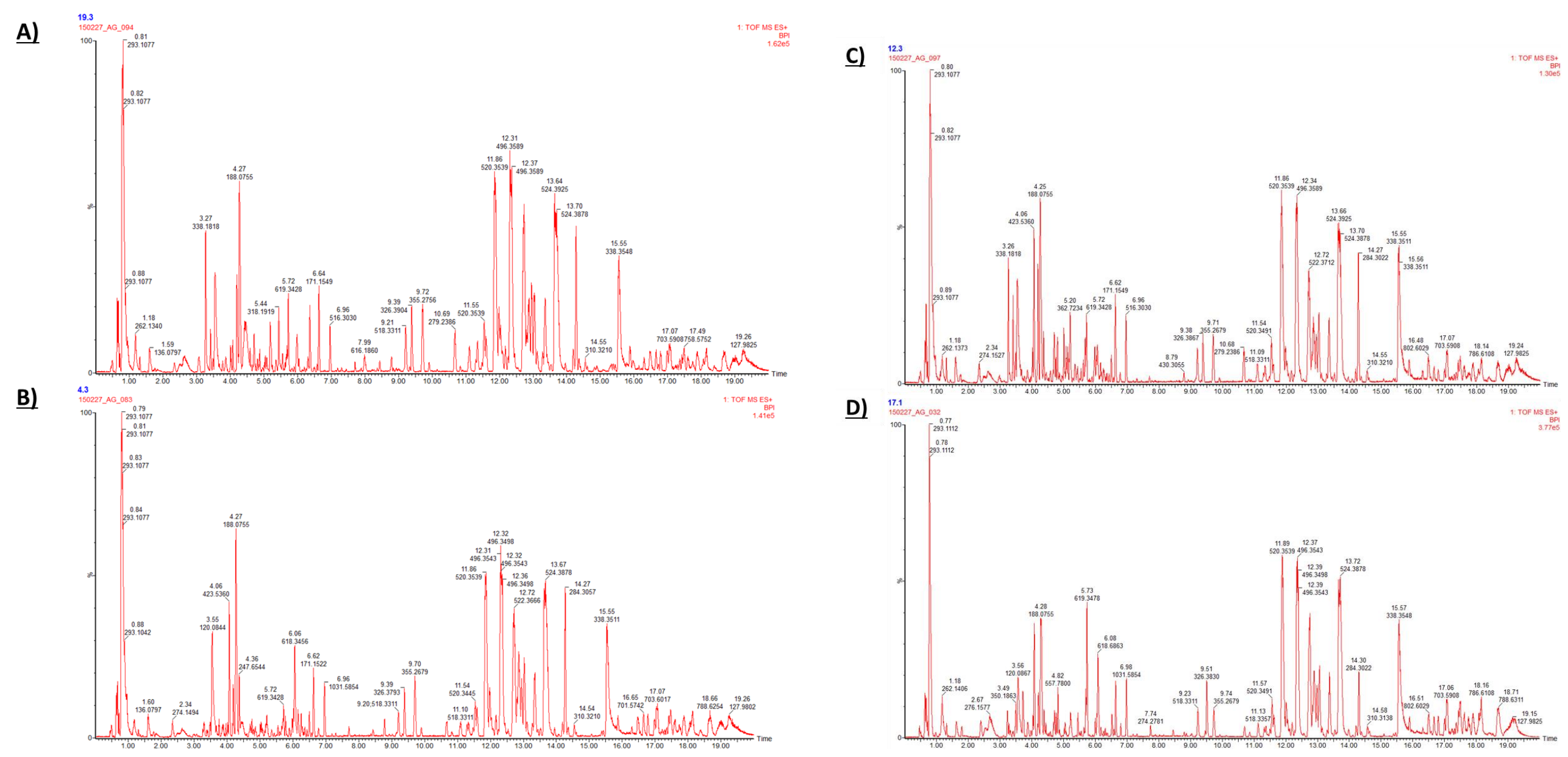


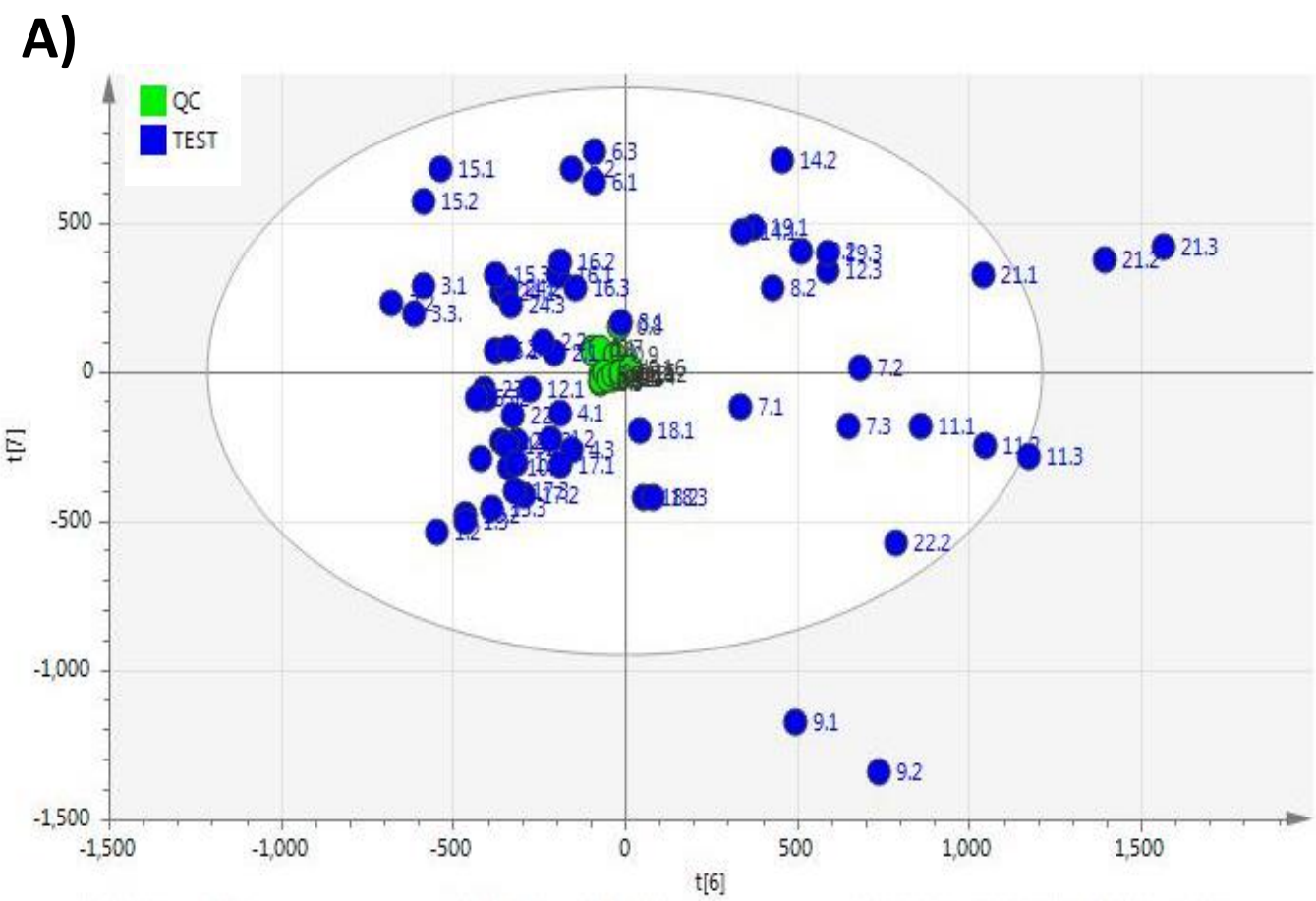

B)

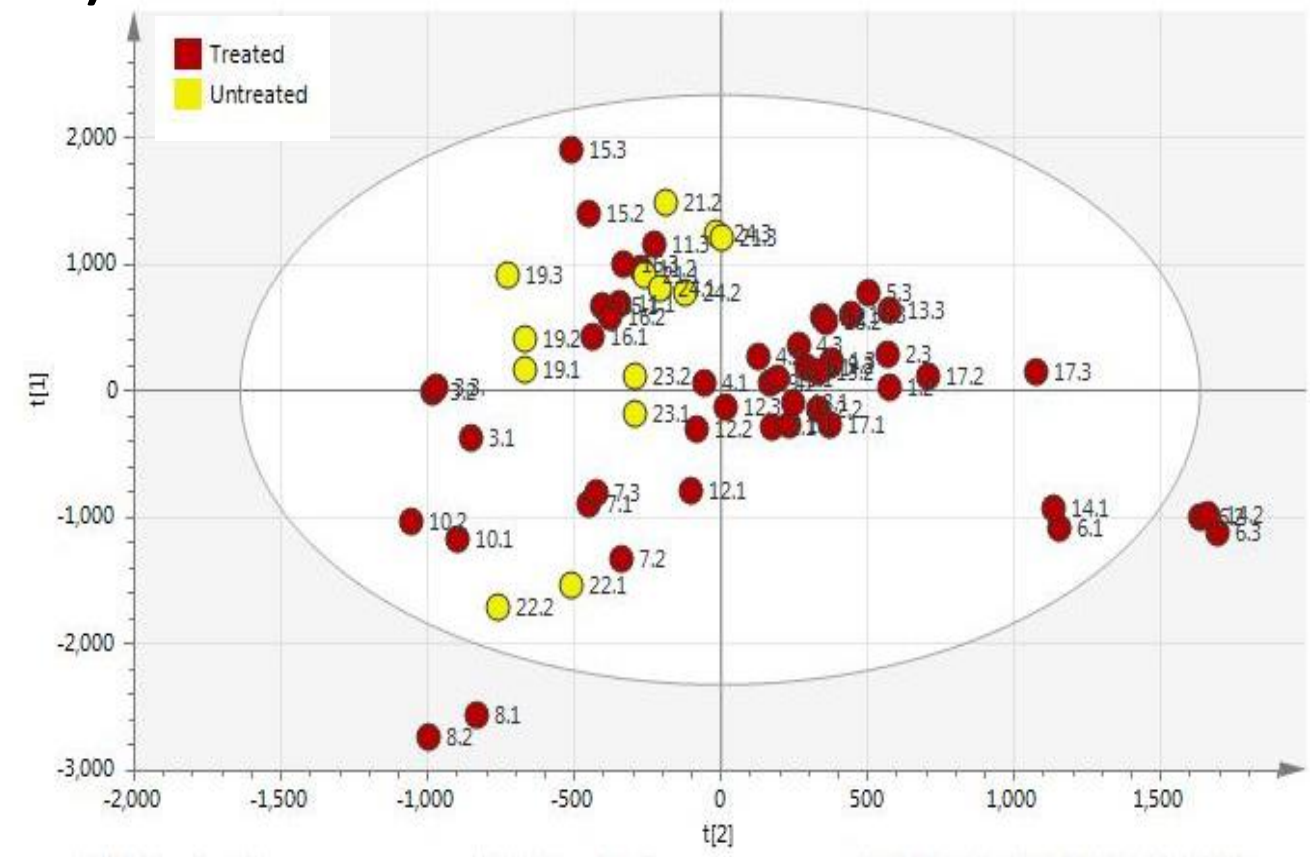


FIGURE 3
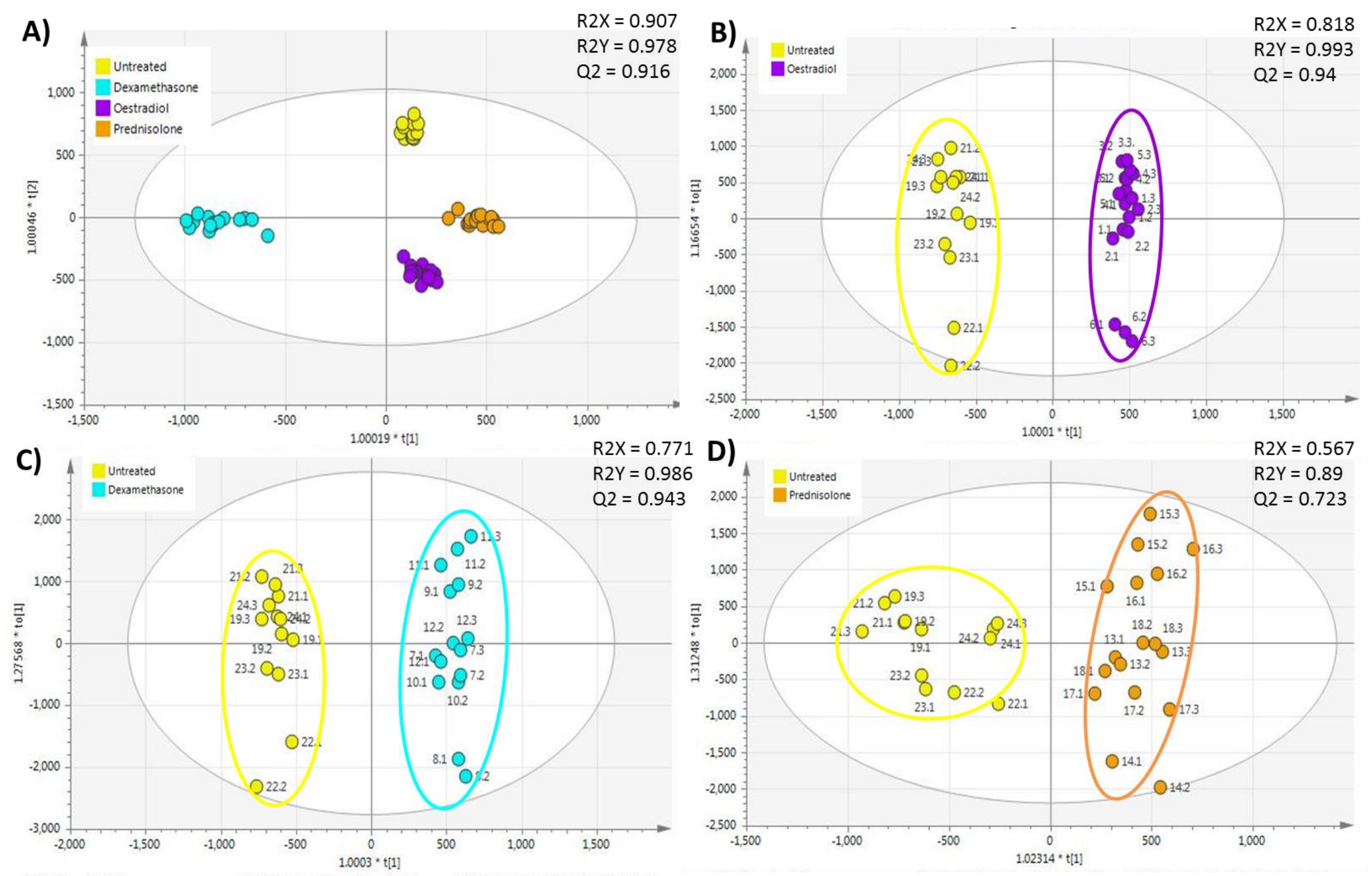
FIGURE 4

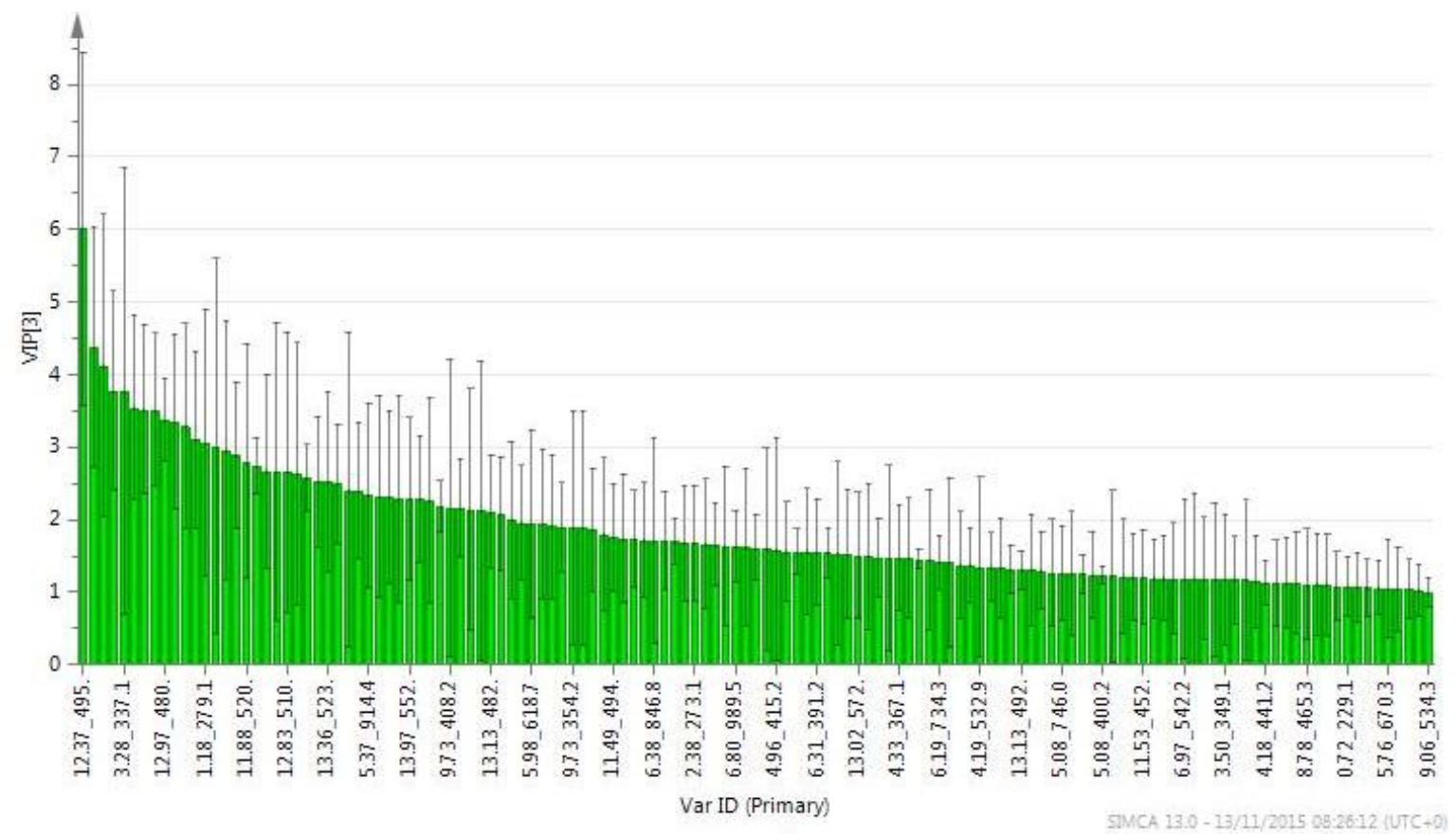


FIGURE 5

\section{A)}

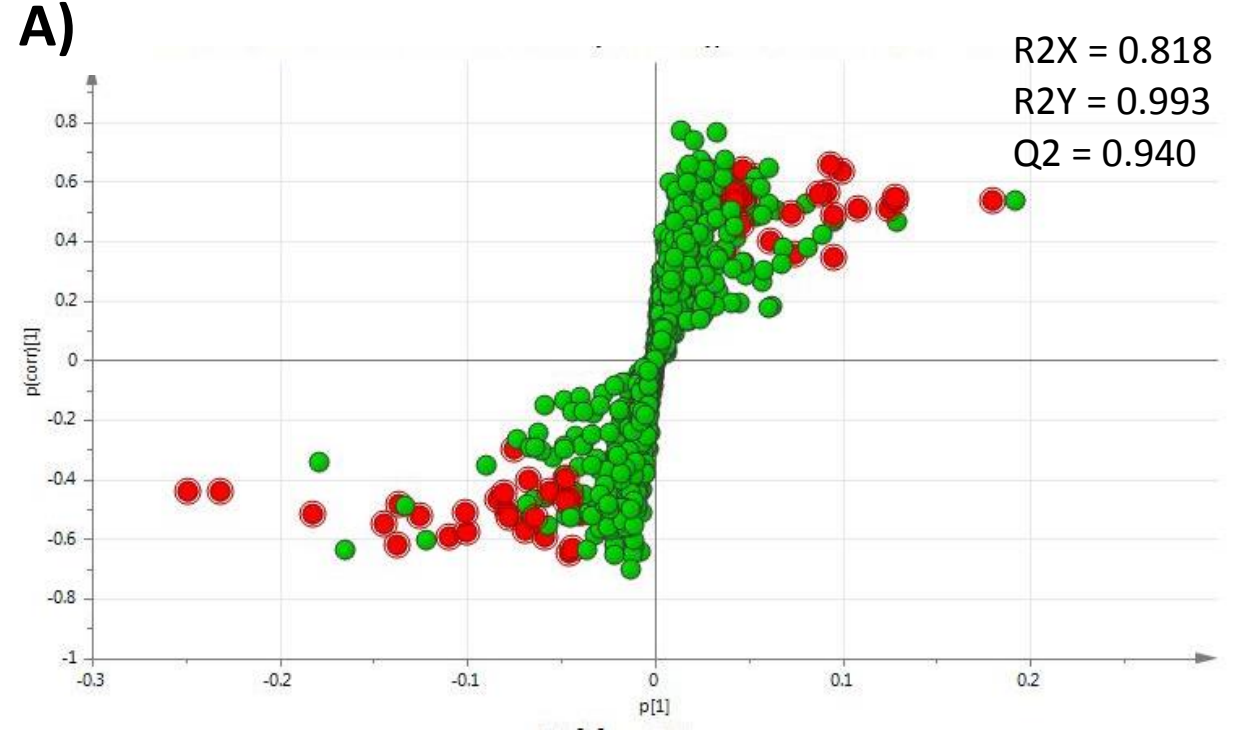

C)

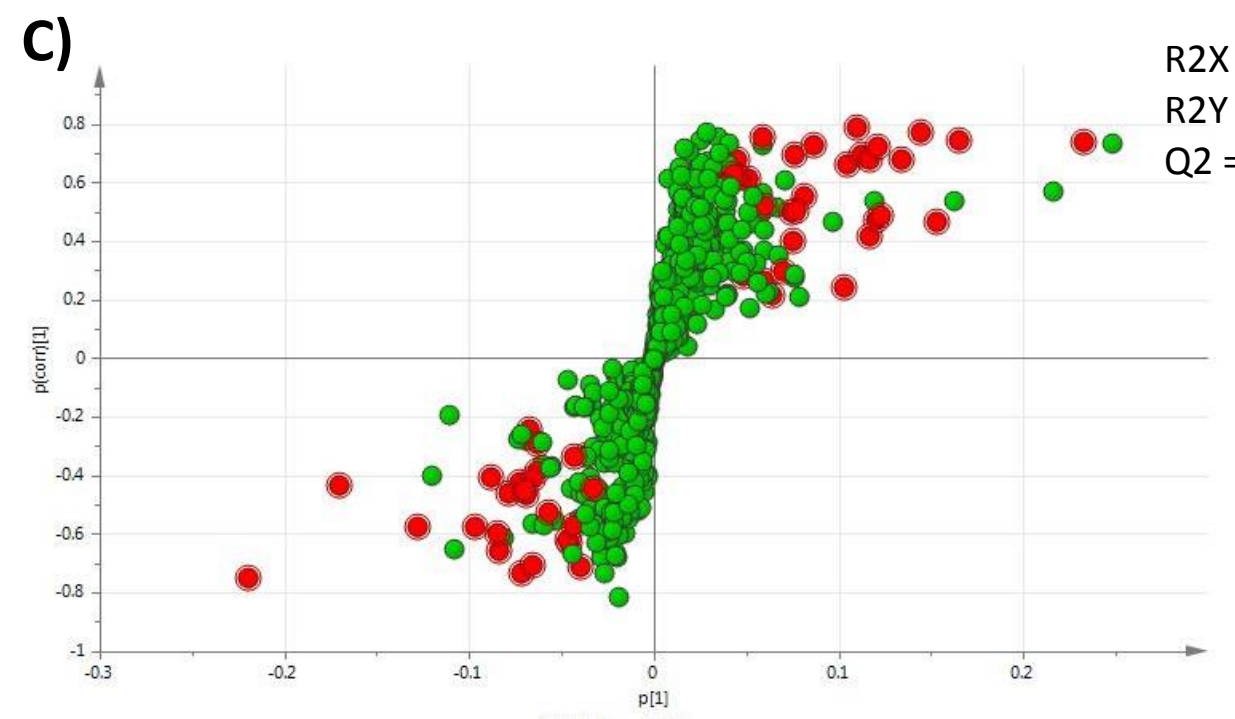

$\mathrm{R} 2 \mathrm{X}=0.771$

$\mathrm{R} 2 \mathrm{Y}=0.986$

$\mathrm{Q} 2=0.943$

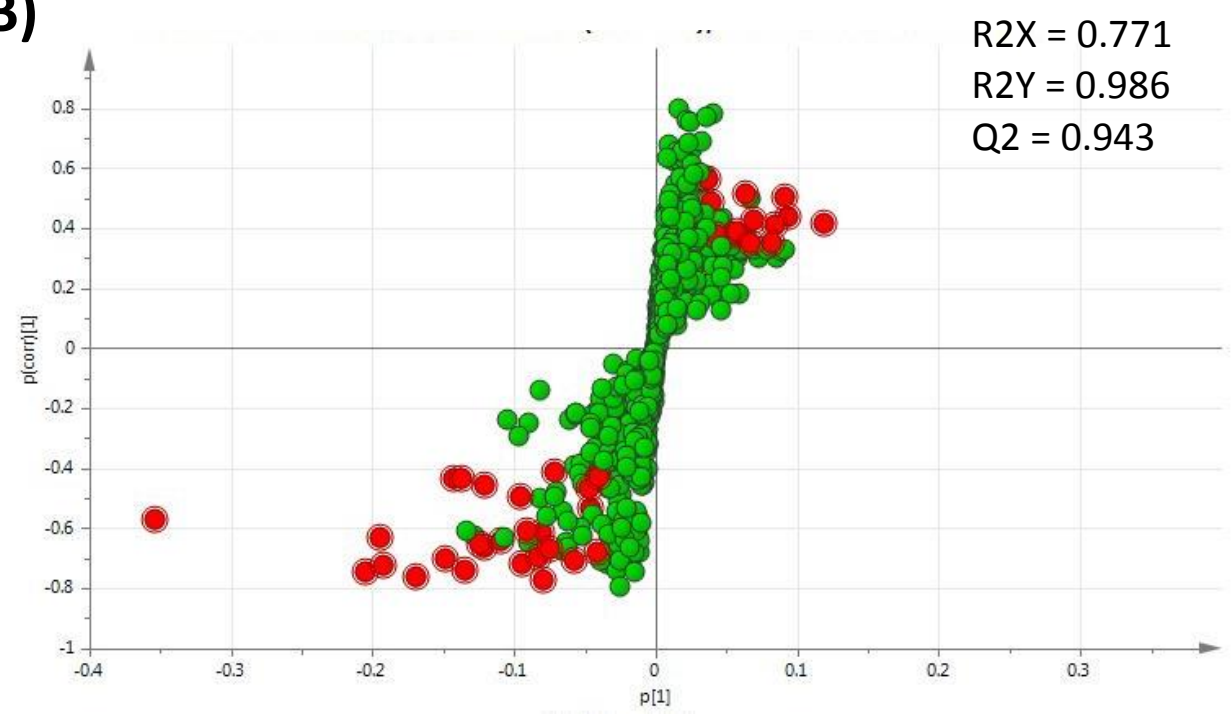

$R 2 X=0.567$

$R 2 Y=0.89$

$=0.723$ 
A)

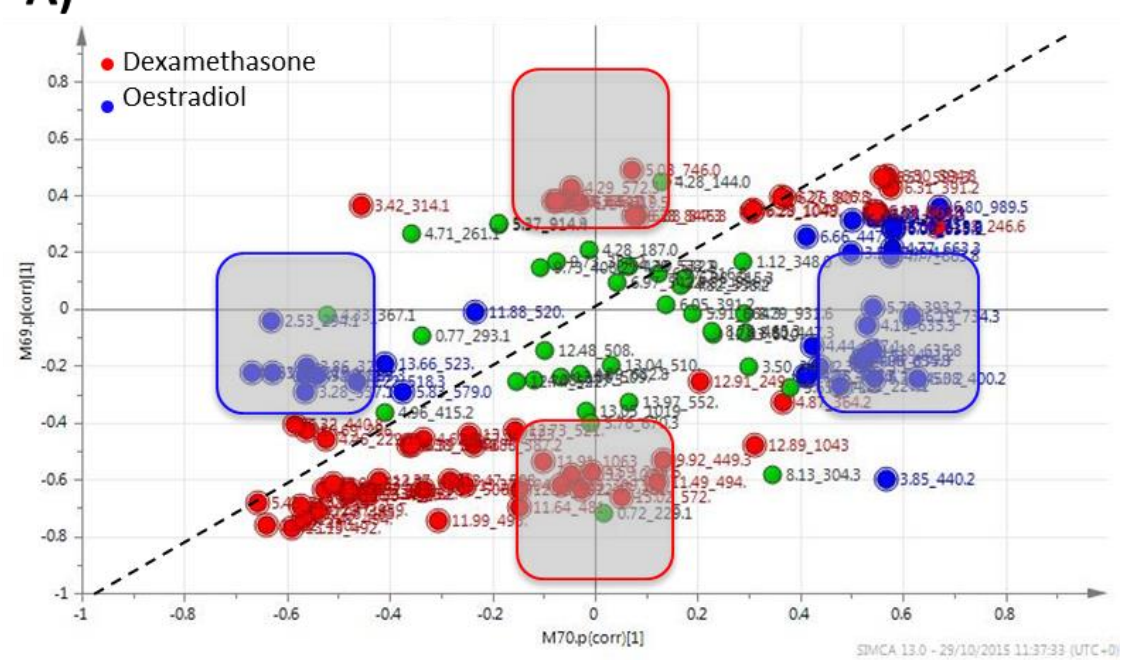

B)

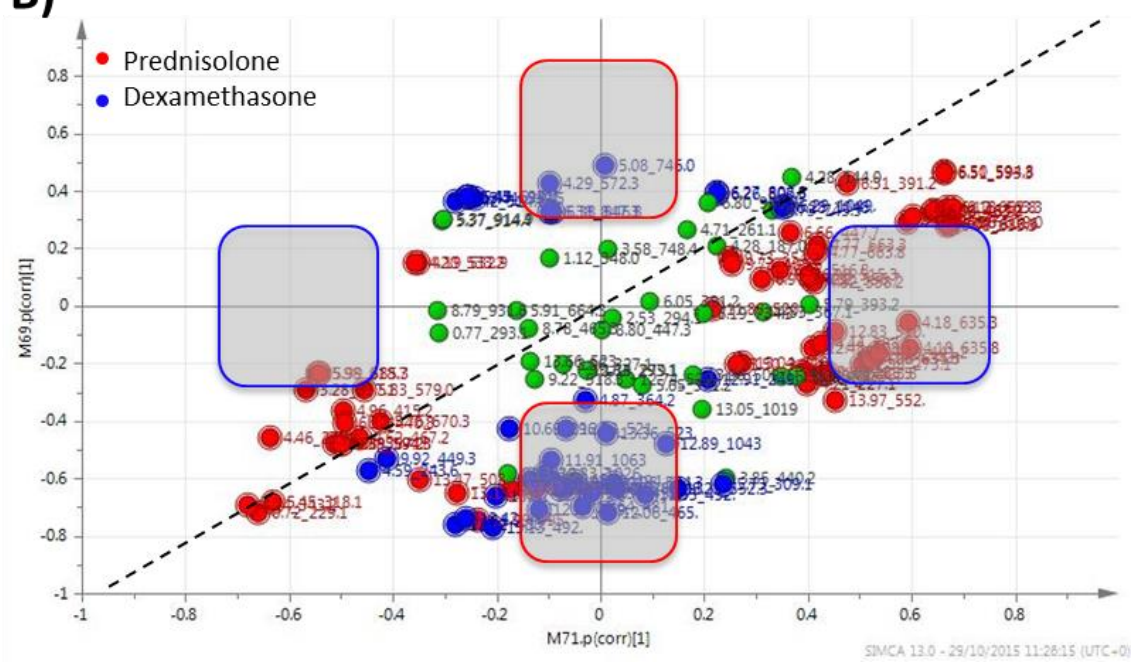

C)

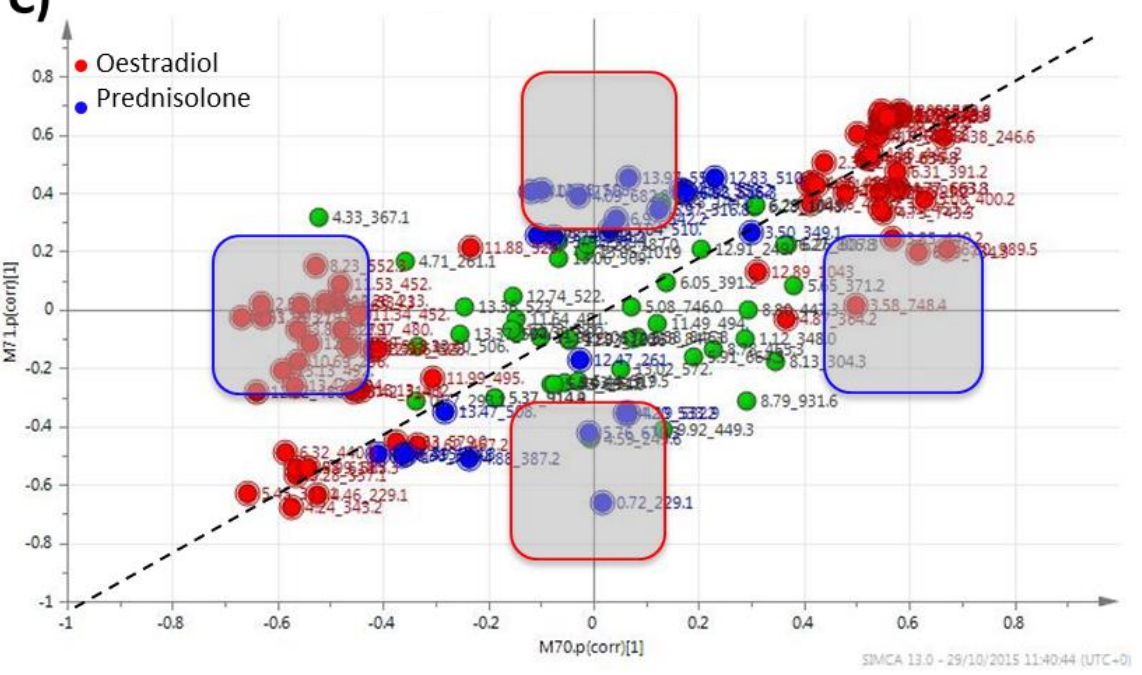

D)

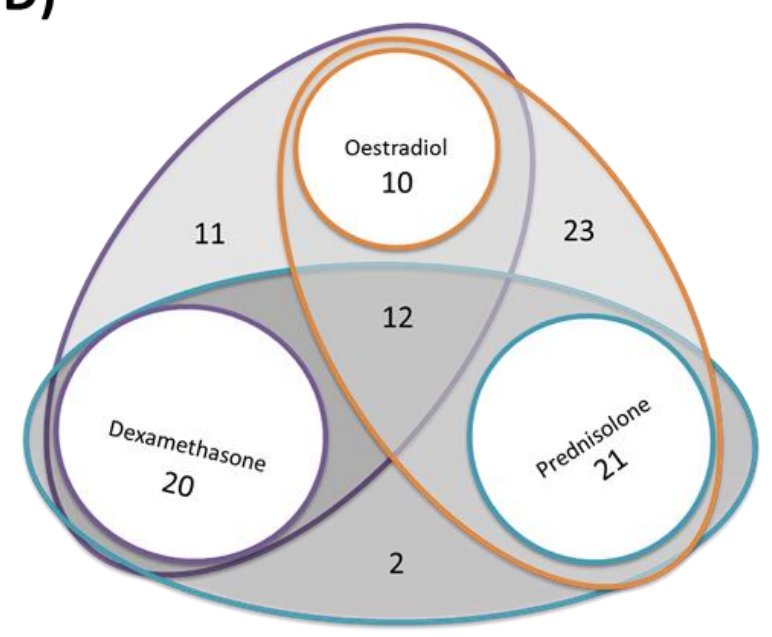




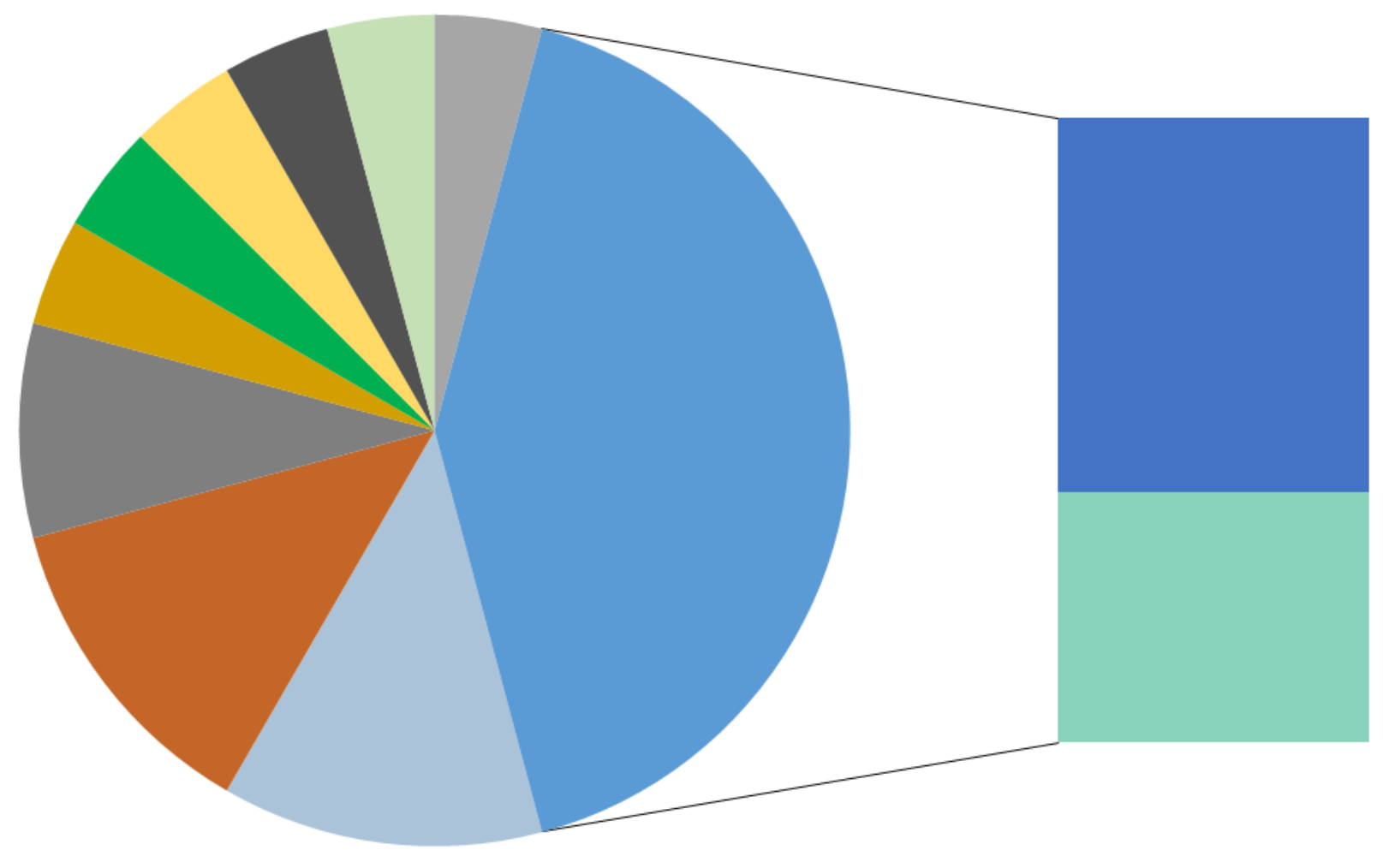

- FATTY ACYL

ACYLCARNITINE

- DIPEPTIDE

- EICOSANOID

- BILE ACID

INDOLE

- VITAMIN DERIVATIVE

STEROID METABOLITE

- UNKNOWN

- LIPIDS

- Phospholipids

॥ Sphingolipids 


\begin{tabular}{|c|c|c|c|c|c|c|c|c|}
\hline \multirow[b]{2}{*}{ AMRTP } & \multirow{2}{*}{$\begin{array}{c}\text { UNTREATED } \\
\text { Peak } \\
\text { Output }\end{array}$} & \multicolumn{2}{|c|}{ Oestradiol } & \multicolumn{2}{|c|}{ Dexamethasone } & \multicolumn{2}{|c|}{ Prednisolone } & \multirow[b]{2}{*}{ VIP } \\
\hline & & $F C$ & $p$ & $F C$ & & $F C$ & & \\
\hline 3.77_312.1489m/z & 660 & 4.07 & 0.066 & 3.88 & 0.038 & 1.81 & 0.250 & 1.2 \\
\hline 4.41_344.8505m/z & 872 & 4.23 & 0.038 & 3.04 & 0.240 & 3.77 & 0.032 & 1.4 \\
\hline 5.56_437.7554m/z & 1225 & 3.11 & 0.064 & 2.30 & 0.211 & 1.62 & 0.066 & 1.3 \\
\hline 5.80_741.3737m/z & 246 & 10.75 & 0.065 & 6.76 & 0.293 & 8.72 & 0.028 & 1.3 \\
\hline $6.08 \_463.0078 n$ & 3415 & 6.87 & 0.092 & 1.97 & 0.419 & 5.04 & 0.022 & 1.2 \\
\hline 6.07_618.6912m/z & 16072 & 3.40 & 0.074 & 1.52 & 0.484 & 3.34 & 0.013 & 2.4 \\
\hline 6.17_662.8879m/z & 8069 & 2.43 & 0.117 & 1.55 & 0.357 & 2.56 & 0.017 & 2.0 \\
\hline $6.18 \_442.2595 \mathrm{~m} / \mathrm{z}$ & 2180 & 2.32 & 0.137 & 1.60 & 0.345 & 2.89 & 0.031 & 1.5 \\
\hline 6.31_391.2184n & 9545 & 1.91 & 0.097 & 1.72 & 0.251 & 1.51 & 0.207 & 1.6 \\
\hline 6.51_593.3530n & 10254 & 2.90 & 0.067 & 1.95 & 0.192 & 1.97 & 0.024 & 2.3 \\
\hline 5.04_338.0986m/z & 4161 & 1.53 & 0.063 & 1.53 & 0.147 & 1.30 & 0.181 & 1.1 \\
\hline $6.27 \_806.8828 \mathrm{~m} / \mathrm{z}$ & 8805 & 1.93 & 0.370 & 3.62 & 0.207 & 1.33 & 0.664 & 2.1 \\
\hline 6.80_989.5636m/z & 7695 & 2.04 & 0.028 & 1.51 & 0.372 & 1.26 & 0.648 & 1.6 \\
\hline 4.38_246.6527n & 9928 & 1.98 & 0.037 & 1.34 & 0.443 & 1.83 & 0.067 & 1.7 \\
\hline $6.01 \_560.3267 \mathrm{~m} / \mathrm{z}$ & 2057 & 1.96 & 0.123 & 1.15 & 0.774 & 2.02 & 0.032 & 1.1 \\
\hline 6.59_130.0697m/z & 780 & 1.60 & 0.316 & 1.08 & 0.816 & 2.78 & 0.045 & 1.0 \\
\hline 3.40_381.7018n & 3260 & 1.62 & 0.159 & 1.43 & 0.389 & 1.19 & 0.594 & 1.2 \\
\hline 3.50_349.1792n & 9427 & 1.55 & 0.377 & 0.68 & 0.376 & 1.39 & 0.471 & 1.2 \\
\hline 3.98_506.6963n & 3283 & 1.78 & 0.119 & 1.33 & 0.539 & 1.21 & 0.632 & 1.3 \\
\hline $3.42 \_314.1654 n$ & 10285 & 0.58 & 0.199 & 1.72 & 0.256 & 0.71 & 0.381 & 1.7 \\
\hline 4.19_532.9512m/z & 8787 & 1.08 & 0.917 & 1.83 & 0.619 & 0.50 & 0.365 & 1.3 \\
\hline 4.29_572.3757m/z & 15060 & 0.89 & 0.839 & 1.95 & 0.182 & 0.81 & 0.623 & 1.9 \\
\hline 4.30_473.3004m/z & 1928 & 0.87 & 0.864 & 2.21 & 0.218 & 0.54 & 0.362 & 1.0 \\
\hline 5.26_340.1144m/z & 1693 & 1.36 & 0.240 & 2.06 & 0.044 & 1.49 & 0.104 & 1.1 \\
\hline 5.45_694.0660m/z & 5424 & 0.80 & 0.808 & 2.65 & 0.224 & 0.54 & 0.376 & 1.8 \\
\hline 6.29_1049.5044n & 6745 & 1.10 & 0.805 & 1.64 & 0.411 & 1.47 & 0.442 & 1.5 \\
\hline $6.38 \_846.8671 \mathrm{~m} / \mathrm{z}$ & 10334 & 0.88 & 0.847 & 2.12 & 0.371 & 0.67 & 0.622 & 1.7 \\
\hline $4.07 \_423.5427 \mathrm{~m} / \mathrm{z}$ & 42359 & 1.37 & 0.259 & 0.75 & 0.367 & 1.67 & 0.130 & 4.4 \\
\hline $4.08 \_477.5618 \mathrm{~m} / \mathrm{z}$ & 2226 & 0.82 & 0.636 & 0.62 & 0.376 & 1.83 & 0.143 & 2.3 \\
\hline 4.68_285.6390n & 5848 & 1.34 & 0.363 & 1.12 & 0.708 & 1.52 & 0.165 & 1.2 \\
\hline 4.82_556.7827n & 24546 & 1.19 & 0.684 & 0.98 & 0.960 & 1.51 & 0.236 & 3.2 \\
\hline 13.97_552.4253m/z & 13655 & 1.08 & 0.747 & 0.73 & 0.373 & 1.62 & 0.196 & 2.3 \\
\hline
\end{tabular}


TABLE 1b

\begin{tabular}{|c|c|c|c|c|c|c|c|c|}
\hline \multirow{2}{*}{ AMRTP } & \multirow{2}{*}{$\begin{array}{c}\text { UNTREATED } \\
\text { Peak } \\
\text { Output }\end{array}$} & \multicolumn{2}{|c|}{ Oestradiol } & \multicolumn{2}{|c|}{ Dexamethasone } & \multicolumn{2}{|c|}{ Prednisolone } & \multirow{2}{*}{ VIP } \\
\hline & & $F C$ & $p$ & $F C$ & $p$ & $F C$ & $p$ & \\
\hline 4.00_393.7204n & 11219 & 0.20 & 0.122 & 0.38 & 0.207 & 0.25 & 0.141 & 1.6 \\
\hline 4.46_229.1634m/z & 31223 & 0.32 & 0.176 & 0.37 & 0.208 & 0.18 & 0.119 & 3.5 \\
\hline $4.96 \_415.2549 n$ & 8338 & 0.13 & 0.193 & 0.36 & 0.314 & 0.09 & 0.176 & 1.6 \\
\hline 5.83_579.0046n & 4361 & 0.08 & 0.305 & 0.43 & 0.502 & 0.06 & 0.295 & 1.2 \\
\hline 6.00_394.2106m/z & 2559 & 0.11 & 0.061 & 0.46 & 0.227 & 0.16 & 0.071 & 1.2 \\
\hline $6.32 \_440.8133 m / z$ & 3093 & 0.14 & 0.251 & 0.25 & 0.308 & 0.13 & 0.246 & 1.1 \\
\hline $6.38 \_594.8657 \mathrm{~m} / \mathrm{z}$ & 8444 & 0.50 & 0.476 & 0.22 & 0.243 & 0.29 & 0.280 & 1.7 \\
\hline 8.23_552.3425m/z & 7757 & 0.40 & 0.114 & 0.23 & 0.022 & 1.22 & 0.779 & 1.7 \\
\hline 3.08_203.1468m/z & 3579 & 0.37 & 0.207 & 0.57 & 0.462 & 0.28 & 0.161 & 1.2 \\
\hline 3.28_337.1815n & 70619 & 0.27 & 0.125 & 0.53 & 0.244 & 0.27 & 0.127 & 3.8 \\
\hline 5.98_618.7759m/z & 20357 & 0.24 & 0.110 & 0.64 & 0.390 & 0.30 & 0.132 & 1.9 \\
\hline 9.94_561.3523n & 1830 & 0.21 & 0.114 & 0.72 & 0.483 & 0.39 & 0.168 & 1.1 \\
\hline $11.42 \_228.2382 \mathrm{~m} / \mathrm{z}$ & 2856 & 0.27 & 0.028 & 0.57 & 0.290 & 0.44 & 0.076 & 1.2 \\
\hline $0.72 \_229.1280 \mathrm{~m} / \mathrm{z}$ & 1342 & 1.07 & 0.909 & 0.22 & 0.069 & 0.24 & 0.073 & 1.1 \\
\hline $4.24 \_344.2161 \mathrm{~m} / \mathrm{z}$ & 4795 & 0.67 & 0.224 & 0.35 & 0.022 & 0.40 & 0.032 & 1.5 \\
\hline 4.89_388.7325m/z & 1794 & 0.58 & 0.537 & 0.28 & 0.218 & 0.34 & 0.293 & 1.0 \\
\hline 10.69_296.2437n & 21128 & 0.47 & 0.102 & 0.65 & 0.288 & 0.78 & 0.567 & 1.9 \\
\hline 5.45_318.1921m/z & 10303 & 0.52 & 0.086 & 0.33 & 0.021 & 0.55 & 0.128 & 1.7 \\
\hline 11.34_452.3281m/z & 27232 & 0.79 & 0.411 & 0.42 & 0.036 & 1.03 & 0.937 & 1.9 \\
\hline 11.49_494.3394m/z & 14328 & 1.17 & 0.576 & 0.46 & 0.061 & 0.99 & 0.964 & 1.8 \\
\hline 11.64_481.3341n & 37684 & 0.95 & 0.833 & 0.40 & 0.022 & 0.99 & 0.984 & 2.5 \\
\hline 11.99_495.3517n & 74675 & 0.88 & 0.495 & 0.45 & 0.010 & 0.89 & 0.547 & 3.5 \\
\hline 12.06_465.3376n & 60724 & 0.74 & 0.256 & 0.41 & 0.019 & 1.08 & 0.820 & 3.4 \\
\hline $12.82 \_480.3605 \mathrm{~m} / \mathrm{z}$ & 37793 & 0.55 & 0.078 & 0.32 & 0.012 & 0.79 & 0.532 & 2.7 \\
\hline 12.97_959.7157m/z & 9751 & 0.51 & 0.164 & 0.15 & 0.062 & 0.85 & 0.794 & 1.5 \\
\hline 13.13_482.3789m/z & 26818 & 0.72 & 0.331 & 0.40 & 0.050 & 0.77 & 0.478 & 2.1 \\
\hline 13.30_506.3807m/z & 22355 & 0.82 & 0.500 & 0.43 & 0.052 & 0.91 & 0.813 & 1.6 \\
\hline $13.42 \_494.3792 \mathrm{~m} / \mathrm{z}$ & 24518 & 0.61 & 0.194 & 0.33 & 0.049 & 0.80 & 0.555 & 2.2 \\
\hline 13.47_508.3950m/z & 16785 & 0.87 & 0.647 & 0.45 & 0.092 & 0.71 & 0.333 & 1.9 \\
\hline
\end{tabular}


804

\begin{tabular}{|c|c|c|c|c|c|c|c|c|c|c|c|c|c|}
\hline Treatment & FC & $p$ & $m / z$ & $\begin{array}{c}\text { RT } \\
(\min )\end{array}$ & $\begin{array}{l}\text { Isotope } \\
\text { Charge }\end{array}$ & $\begin{array}{l}\text { Elemental } \\
\text { Composition }\end{array}$ & Mass & Adduct & MW & $\begin{array}{c}\text { Mass } \\
\text { Diff } \\
\text { (mDa) }\end{array}$ & Compound & $\begin{array}{c}\text { CID } \\
\text { (PubChem) }\end{array}$ & Class \\
\hline $\begin{array}{l}\text { Oestradiol } \\
\text { Prednisolone }\end{array}$ & + & $\begin{array}{l}0.038 \\
0.032\end{array}$ & 344.8505 & 4.41 & $\begin{array}{l}344.8449+++ \\
>516.7748++ \\
>1032.5249+\end{array}$ & $\mathrm{C}_{48} \mathrm{H}_{89} \mathrm{~N}_{3} \mathrm{O}_{15} \mathrm{P}_{2}$ & 1032.5661 & $\mathrm{M}+\mathrm{Na}$ & 1009.58 & $-36.10^{*}$ & CDP-DG(18:0/18:0) & 53477922 & Glycerophospholipid \\
\hline \begin{tabular}{|} 
Dexamethasone \\
Prednisolone
\end{tabular} & - & $\begin{array}{l}0.022 \\
0.032\end{array}$ & 344.2161 & 4.24 & \begin{tabular}{|l|}
$344.1996++$ \\
$>687.3996+$
\end{tabular} & $\mathrm{C}_{36} \mathrm{H}_{63} \mathrm{O}_{10} \mathrm{P}$ & 344.2152 & $\mathrm{M}+2 \mathrm{H}$ & 686.42 & 0.94 & $\begin{array}{l}P G(18: 4(6 Z, 9 Z \\
12 Z, 15 Z) / 12: 0)\end{array}$ & 52926690 & Glycerophospholipid \\
\hline Oestradiol & + & 0.028 & 989.5636 & 6.80 & $989.5685+$ & $\mathrm{C}_{45} \mathrm{H}_{90} \mathrm{~N}_{3} \mathrm{O}_{14} \mathrm{P}_{3}$ & & & & & Unknown & & \\
\hline Oestradiol & + & 0.037 & 247.6600 & 4.38 & $\begin{array}{l}247.6608++ \\
>494.3061+\end{array}$ & $\mathrm{C}_{24} \mathrm{H}_{48} \mathrm{NO}_{7} \mathrm{P}$ & 247.6657 & $\mathrm{M}+2 \mathrm{H}$ & 493.32 & -5.71 & LysoPC(16:1(9z)) & 24779461 & Glycerophospholipid \\
\hline Oestradiol & - & 0.028 & 228.2382 & 11.42 & $228.2345+$ & $\mathrm{C}_{14} \mathrm{H}_{27} \mathrm{NO}_{4}$ & 228.2228 & $\mathrm{M}+2 \mathrm{Na}+\mathrm{H}$ & 273.19 & 11.50 & Heptanoylcarnitine & 6426896 & Acylcarnitine \\
\hline Dexamethasone & + & 0.038 & 312.1489 & 3.77 & $312.1359+++$ & $\mathrm{C}_{28} \mathrm{H}_{42} \mathrm{~N}_{7} \mathrm{O}_{18} \mathrm{P}_{3} \mathrm{~S}$ & 312.1502 & $\mathrm{M}+\mathrm{H}+2 \mathrm{Na}$ & 889.15 & -1.29 & $\begin{array}{c}\text { 6-Oxocyclohex-1-ene- } \\
\text { 1-carboxyl-CoA }\end{array}$ & 442450 & Fatty Acyl Thioesters \\
\hline Dexamethasone & + & 0.044 & 340.1144 & 5.26 & $340.1026+$ & $\mathrm{C}_{16} \mathrm{H}_{19} \mathrm{~N}_{3} \mathrm{O}_{3}$ & 340.1058 & $\mathrm{M}+\mathrm{H}$ & 301.34 & 8.55 & Tryptophyl-Proline & 23980\# & Dipeptide \\
\hline \begin{tabular}{|l|} 
Dexamethasone \\
\end{tabular} & + & 0.022 & 552.3425 & 8.23 & $552.3353+$ & $\mathrm{C}_{26} \mathrm{H}_{54} \mathrm{NO}_{6} \mathrm{P}$ & 552.3400 & $\mathrm{M}+2 \mathrm{Na}-\mathrm{H}$ & 507.37 & 2.50 & $\mathrm{PC}(0-18: 1(11 Z) / 0: 0)$ & 21672239 & Glycerophospholipid \\
\hline Dexamethasone & + & 0.021 & 318.1921 & 5.45 & $318.1846+$ & $\mathrm{C}_{17} \mathrm{H}_{23} \mathrm{~N}_{3} \mathrm{O}_{3}$ & 318.1812 & $\mathrm{M}+\mathrm{H}$ & 317.17 & 10.93 & Isoleucyl-Tryptophan & 85823\# & Dipeptide \\
\hline \begin{tabular}{|l|} 
Dexamethasone \\
\end{tabular} & - & 0.036 & 452.3281 & 11.34 & $452.3184+$ & $\mathrm{C}_{25} \mathrm{H}_{41} \mathrm{NO}_{4}$ & 452.3370 & $\mathrm{M}+\mathrm{CH}_{3} \mathrm{OH}+\mathrm{H}$ & 419.30 & -8.94 & Stearidonyl carnitine & 53477835 & Acylcarnitine \\
\hline Dexamethasone & - & 0.022 & 482.3414 & 11.64 & 482.3299+ & $\mathrm{C}_{23} \mathrm{H}_{48} \mathrm{NO}_{7} \mathrm{P}$ & 482.3476 & $\mathrm{M}+\mathrm{CH}_{3} \mathrm{OH}+\mathrm{H}$ & 449.31 & -6.19 & $\begin{array}{c}\text { Chenodeoxycholic acid } \\
\text { glycine conjugate }\end{array}$ & 12544 & Bile acid \\
\hline Dexamethasone & - & 0.010 & 496.3590 & 11.99 & $496.3498+$ & $\mathrm{C}_{30} \mathrm{H}_{51} \mathrm{NO}_{2}$ & 496.3551 & $\mathrm{M}+\mathrm{K}$ & 457.39 & 3.90 & $\begin{array}{c}\text { 3'-O-Aminopropyl-25- } \\
\text { hydroxyvitamin D3 }\end{array}$ & 12020395 & Secosteroid \\
\hline Dexamethasone & - & 0.019 & 466.3449 & 12.06 & $466.3354+$ & $\mathrm{C}_{25} \mathrm{H}_{49} \mathrm{NO}_{5}$ & 466.3503 & $\mathrm{M}+\mathrm{Na}$ & 443.36 & -5.37 & $\begin{array}{c}\text { 12-Hydroxy-12- } \\
\text { octadecanoylcarnitine }\end{array}$ & 53481632 & Acylcarnitine \\
\hline Dexamethasone & - & 0.012 & 480.3605 & 12.82 & $480.3422+$ & $\mathrm{C}_{27} \mathrm{H}_{45} \mathrm{NO}_{4}$ & 480.3683 & $\mathrm{M}+\mathrm{CH}_{3} \mathrm{OH}+\mathrm{H}$ & 447.33 & -7.80 & N-stearoyl tyrosine & 6710116 & Fatty Acyl Amide \\
\hline Dexamethasone & - & 0.050 & 482.3789 & 13.13 & $482.3703+$ & $\mathrm{C}_{33} \mathrm{H}_{49} \mathrm{~N}$ & 482.3757 & $\mathrm{M}+\mathrm{Na}$ & 459.39 & 3.18 & $\begin{array}{c}\text { 1'H-5alpha-Cholest-2- } \\
\text { eno[3,2-b]indole }\end{array}$ & 17396442 & Steroid Metabolite \\
\hline Dexamethasone & - & 0.049 & 494.3792 & 13.42 & $494.3606+$ & $\mathrm{C}_{10} \mathrm{H}_{23} \mathrm{~N}_{3} \mathrm{O}_{3}$ & 494.3710 & $2 \mathrm{M}+3 \mathrm{H} 2 \mathrm{O}+2 \mathrm{H}$ & 455.40 & 8.15 & Hypusine & 65396 & Hydroxy Fatty Acyl \\
\hline
\end{tabular}


TABLE 2 cont'd

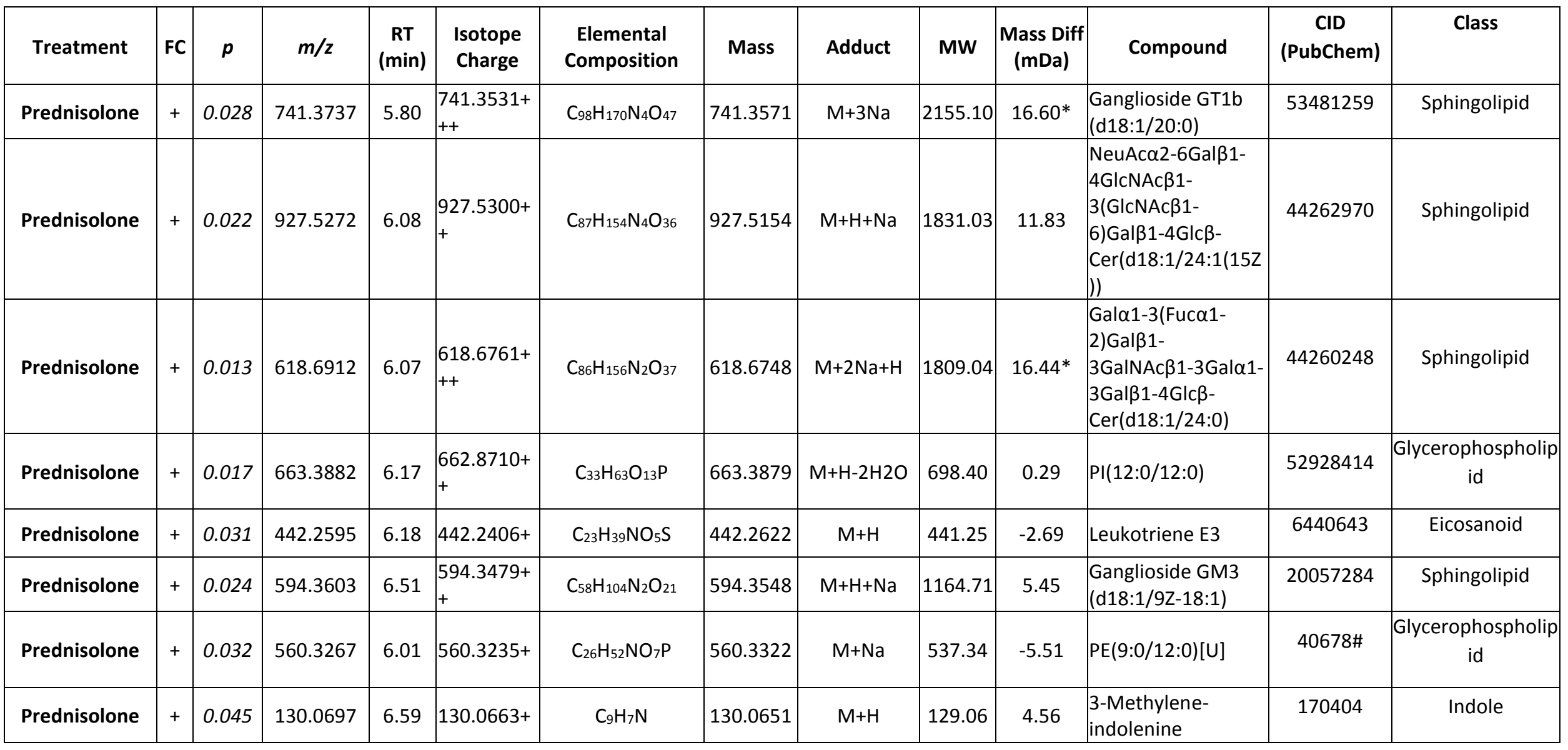

